\title{
Gendered Pathways to Science: The Perceived Impact of Social Ties and Individual Preferences
}

\author{
Estelle Danilo $\quad$ Youjia Shi Gabriela Pflaumer
}

Department of Sociology

Columbia University, NY

(C) 2018 Danilo, Shi, Pflaumer. This is an open access article distributed under the terms of the Creative Commons Attribution License, which permits the user to copy, distribute, and transmit the work provided that the original author(s) and source are credited. 


\begin{abstract}
Despite the huge effort taken to promote gender parity in Science Technology Engineering and Mathematics education, women remain overwhelmingly underrepresented in these fields. Current literature has demonstrated that there are significant processes that influence whether or not someone pursues STEM; yet, none of them specify the perceived individual and environmental factors that correlate with persistence in STEM education. Ergo, the focus of this paper is to try to account for the individual and social causes of persistence in pursuing STEM studies, as perceived by women and men who chose and continued to study STEM at college; more specifically, the nature, timing, and relative influence of these perceived determinants and how they vary according to gender. We have not followed a traditional quantitative research protocol that reaches causal claims. Instead, we have used self-reported retrospective data that offer subjective insight into the perceived determining factors to enter the pathway to STEM at college. To do so, we have conducted a survey, situating STEM undergraduate students at Columbia University in a sequence of events, influences, interactions, and institutions that are successively associated with their current orientation towards STEM disciplines. This research design has enabled us to look at the relative perceived influence of their social ties and individual preferences at three different stages of their life. While men and women who chose to major in STEM do not seem to have fundamentally different perceived individual preferences, they do seem to perceive the contribution of their social environment to their interest in science differently.
\end{abstract}

\title{
Table of Content
}

Abstract 


\section{Problem Statement}

Background

Overall Design

Method Justification

Population and Survey Distribution

Survey Question Format

Question Design / Data Collected

- Perceived Individual Factors

- Perceived Social Factors

\section{Results}

- Perceived Individual Factors

○ Hypothesis 1: Perceived Personality Traits Do Not Differ by Gender

○ Hypothesis 2: Perceived Interest and Performance in Mathematics Do Not Differ by Gender

- Perceived Social Factors

○ Hypothesis 3: Perceived Local Networks (Family, School, Peer Influence) Differ by Gender

○ Hypothesis 4: College Club Membership Differs by Gender

- Hypothesis 5: Perceived STEM Community Integration at College Differs by Gender

- Hypothesis 6: Perceived Confrontation with Male versus Female Professor Differs by Gender

○ Hypothesis 7: Peer Study Group Differs by Gender

- Hypothesis 8: Perceived Influence of Public Figures Does Not Differ by Gender

○ Hypothesis 9: Perceived Influence of Objects Differs by Gender

\section{Limitations}

Conclusion

\section{Acknowledgements}

Fig. 1 Sample personality traits question

Fig. 2 Sample interest / performance question in primary school

Fig. 3 Sample family, teacher, peer influence question in high school

Fig. 4 Sample academic STEM community integration question at college 
Fig. 5 Sample respondent-professor dynamics question at college

Fig. 6 Gender distribution of respondents

Fig. 7 Major distribution of respondents

Fig. 8 Average perception of scientific problem (scaled from -5 to +5 , female student as pink and male student as blue)

Fig. 9 Personality trait by gender: thinker/doer/observer

Fig. 10 Personality trait by gender: challenge oneself/compete/find solutions

Fig. 11 Personality trait by gender: planner/leader/implementer

Fig. 12 Average female and male scores of interest and perceived performance in mathematics over time (scaled from -5 to 5 )

Fig. 13 Average percentage of importance attributed to each criteria (field) in choosing a career; for men (first column) and women (second column)

Fig. 14 Average local network in primary school by gender

Fig. 15 Average local network in high school by gender

Fig. 16 Average local network at college by gender

Fig. 17 Club membership network at college (female student as pink and male student as blue; STEM club as yellow and non-STEM club as beige)

Fig. 18 Number of respondents by gender per level of integration in STEM community at college (core-middleperiphery)

Fig. 19 Number of female and male respondents per answer to question on professor-respondent dynamics at college by gender of professor

Fig. 20 Ego network at college of 7 STEM students with their respective major (female student as pink and male student as blue)

Fig. 21 Network of public figures' influence on students (public figure as square and student as circle, female student as pink and male student as blue)

Fig. 22 Network of objects' influence on students' orientation towards STEM (object as square and student as circle, female student as pink and male student as blue, object as yellow for STEM-related and beige for non-STEM related)

Table 1 Number of respondents per personality trait region by gender: thinker/doer/observer 
Table 2 Number of respondents per personality trait region by gender: challenge oneself/compete/find solutions Table 3 Number of respondents per personality trait region by gender: planner/leader/implementer

Table 4 Average support from social actors in primary school by gender (scaled from -5 to 5 )

Table 5 Average support from social actors in high school by gender (scaled from -5 to 5 )

Table 6 Average support from social actors at college by gender (scaled from -5 to 5 )

Table 7.1 Number of ties (edges) by college club membership and gender of STEM student

Table 7.2 Number of ties (edges) by type of college club and gender

Table 8 Number of respondents by gender per level of integration in STEM community

Table 9 Sum of weighted influence by type of public figure and gender of STEM student (scaled from -5 to 5)

Table 10 Sum of weighted influence by type of object and gender of STEM student (scaled from -5 to 5)

\section{Problem Statement}


The U.S. federal government has long been aware of the importance of supporting and retaining women in STEM (Science, Technology, Engineering and Mathematics) fields ("Women in STEM" 2016; Xie, Fang, and Shauman 2015). Despite a considerable effort in recent years from governmental agencies, educational institutions, and STEM industries to recruit women and increase their retention rate in STEM fields, women remain largely underrepresented. This is especially the case when it comes to certain STEM fields, some of which are traditional fields with a long history of maledominated culture, such as engineering and physical science; while others are quite new, such as computer science ("Women in STEM" 2016; National Science Foundation 2015; Mann and DiPrete 2013). This underrepresentation of women in STEM fields is contradictory and inconsistent, given the amount of women receiving post-secondary degrees.

According to the latest NSF's (National Science Foundation) data, women earned over $57 \%$ of bachelor's degrees in all disciplines from 2004 to 2014. When it comes to degrees in STEM, the NSF dataset shows women holding only $38 \%$ of those degrees; and in fields such as computer science and engineering, the percentage of women is even lower, hovering below 20\%. This discrepancy is even more significant as we turn our attention to the job market, where women only make $25 \%$ of the overall STEM workforce (National Science Foundation 2015, Table 5-1 and Table 9-5). While these numbers confirm the arching gender disparity in STEM education and STEM fields, they also show a tendency for women with STEM degrees to withdraw from these fields. Hence, the aim of this research is to try to detect and uncover some of the perceived factors by which women and men choose and continue to study STEM. By conducting a survey sampling college undergraduate students studying STEM at Columbia University, we hope to bring to light the perceived impact of family, school, peers, and media in these choices; and how these perceived factors may differ according to gender.

\section{Background}

Essentially, there are two main approaches when analyzing why people enter and remain in the fields of STEM. The first focuses on individual aspects by paying attention to why and how some individuals explicitly choose to study STEM. The second approach focuses rather on social forces that may invite or dissuade potential STEM students and/or practitioners - why and how individuals are implicitly chosen into STEM. It is important to point out that these two factors are often interdependent and interconnected with each other. For example, career prospects - environment, culture, pay, etc. tend to heavily influence individual choices. These choices, in turn, shape educational and occupational environments. Indeed, this is a multivariate phenomenon that must be explained by multiple, interrelated, perceived causal factors. These factors are even more prevailing in the way they intersect gender. Gender, here, is seen as a socially produced set of characteristics rather than a product of biological differences; thus following Joan Acker's definition in "Inequality Regimes: Gender, Class, and Race in Organizations" as "socially constructed differences between men and women and the beliefs and identities that support difference and inequality" (2006, 444).

The perception of male superiority has been a dominant factor in the development of STEM education as well as STEM occupation. Biases against women's capacities have constrained them from establishing themselves as legitimate aspirants in STEM fields. Although this antagonism against women persists to this day, plenty of empirical work has shown that biological differences have no 
impact on an individual's science and math competencies (Xie, Fang, and Shauman 2015; Ceci, Williams, and Barnett 2009). What they do show, however, is a difference in their self-assessments and self-confidence in regard to these aptitudes. And while these self-perceived differences are not definable, they do have the power to influence interest, performance, and motivation to study and pursue STEM careers (Xie, Fang, and Shauman 2015; Correll 2001). Rather than inherent differences, what they reflect is a "normative belief" or a "widespread cultural stereotype" regarding gender disposition that assumes that women are naturally less talented and less interested in science than men (Xie, Fang, and Shauman 2015). These "assumed" dispositions are not only woven in the cultural order, but also embedded into one's identity. This has a tremendous impact especially when it comes to STEM education.

Sociologists like Ridgeway and Correll have shown that gender beliefs are hegemonic in the sense that they act as "background identities" $(2004,513)$. Thus, gender beliefs establish gender as a dominant factor for identity formation. According to socialization theories, socialization is a lifelong process "by which people learn the characteristics of their group - the attitudes, values, and actions thought appropriate for them" (Henslin c1996, 73). Gender then becomes the specification from which we organize and negotiate our social relations; and it is upon this structure that we establish our expectations and what we believe to be appropriate gendered behaviors. These social expectations influence individual orientation and behaviors in a profound way. For example, Xie et al. notes that "girls also are more likely than boys to express interest in pursuing people-oriented work, to see science as inconsistent with that orientation, and to perceive the scientific lifestyle as unattractive" (Miller et al. 2006). This attitude seems to reflect the "normative belief" that girls are naturally more inclined to communications and not interested in science. Despite this assumption, gender gaps for participation in mathematics and science are practically non-existent with girls often superseding their male peers (Xie, Fang, and Shauman 2015).

While gender disparities for participation in high school mathematics have disappeared, they continue to manifest significantly in tertiary education. Xie et al. write that "gender disparities in social-psychological determinants of STEM education manifest in consequential ways at the more advanced levels of education" (Xie, Fang, and Shauman 2015, 341). However, it is important to note that although women's participation in STEM majors is growing, this improvement is due to an overall increase in women's enrollment in higher education (Mann \& DiPrete 2013). The gender gap remains significantly large, especially in certain areas of STEM education.

Although many researchers have focused on the "determinants and influence of interest in science and mathematics as the primary factors affecting sex differences in STEM education" (Xie, Fang, and Shauman 2015, 342), they have yet been able to find an explanation for the gender gap in STEM education. Scholars have raised questions focusing on the impact of contextual factors - "the social settings in which the students are situated" (Xie et al. 2015, 334); the impact of family influence in their child's education (Xie et al. 2015); and the impact of individual level-factors in educational outcome (Xie 2012, 6). However, most of the existing research on this topic has tested these social factors independently rather than in conjunction. Therefore, understanding how these different factors come together - be they macro or micro, societal or individual, contextual or intrinsic - and how they shape the individual is extremely important as we try to better understand women's staggering underrepresentation in STEM fields. It can also help us understand why there remains such a stagnant and still relatively high-level of horizontal segregation - the concentration of men and women in different kinds of jobs - within these fields for more than two decades now, in spite of a huge decline in the 1970s and 1980s, and especially, given the fact that women have been outnumbering men in 
earning college degrees for more than a decade now (DiPrete and Buchmann 2013; Mann and DiPrete 2013; National Science Foundation 2015). The underrepresentation of women and gender segregation in STEM fields are problems not only in terms of gender inequality and discrimination, but are also a tremendous disadvantage to a nation's advancement.

The current gender disparity in STEM fields represents a great deficit in knowledge and innovation. It also has important consequences for economic growth as STEM knowledge has and continues to be the backbone of any post-industrial economy. The growth of such "knowledge economy" relies extensively on technological innovation and development. Undeniably, the Knowledge Economy Index (KEI) is seen as a major indicator of a nation's competitiveness, especially in the present era of globalization. According to Xie, demands for a large and talented STEM labor force are essential for America's economic development as policy makers and experts, as well as the general public, regard endless waves of technological innovation as "the primary mechanism by which economic growth can be sustained" (Xie 2012:1). Following this frame, we can understand why the state of American science education has been a topic of so much concern in recent years. Xie et al. argue that "a primary cause of the pessimism [around science] is the widely held perception that STEM education in the United States is woefully inadequate, in both quantity and quality, and unequally available across social groups" (Xie et al. 2015:332). Indeed, this inconsistency of STEM education and its uneven distribution across different social groups is a tremendous disadvantage for the nation's global competitiveness and the advancement of its national research. Our intent is to provide a better understanding of the perceived "processes that promote persistence in STEM education and how those processes vary by gender" to hopefully start a conversation between STEM students and policymakers (Xie 2012:341).

Furthermore, the study on the dynamics of individual choice is of fundamental academic importance in and of itself. Socialization theories view individuals as socialized selves that are influenced by different agents of socialization throughout their life course (Henslin c1996). Unsurprisingly, these social forces are, more often than not, interdependent and interconnected with one another. To that end, by examining four primary agents of socialization - family, school, peer groups and mass media - and how they may collectively appear to influence one's choice to major in STEM, our research can hopefully shed new light in the current understanding of the phenomenon, as perceived by students.

\section{Overall Design}

The aim of our design is to address the gaps in current literature regarding the perceived pathway to STEM with special attention to its intersection with gender. Although current literature demonstrates and correlates many factors that contribute to an education in STEM, none of them provides a systematic and panoramic view of this phenomenon. According to Xie et al., "[social scientists] do not yet fully understand the processes that promote persistence in STEM education and how those processes vary by gender" (Xie et al. 2015:341). In addition, more research efforts have been taken to study the underachievement of certain underrepresented groups such as women; however, "little attention has been paid to the reverse side of the issue: the determinants of the success of certain individuals and social groups in STEM education" and "the nature, timing, and relative impacts of these processes" (Xie et al. 2015). 
In order to answer partially this demand, our research was specifically designed to assess some of the perceived social and individual factors that lead someone into a STEM education. In order to capture this perceived process over time, we have looked at circumstances during three stages: primary school, high school, and college. We have incorporated a wide range of questions designed to examine several individual characteristics as well as social factors. Individual factors include: personality traits, interest and performance in STEM curriculum (mathematics in primary school, mathematics and other introductory science courses in high school, and calculus and other courses related to STEM majors at college). Social factors involve the four primary agents of socialization: family, school, peer groups, and mass media. We followed the three stages format for all of these social factors, except for mass media, where we looked for the overall influence public figures and other items (i.e. books, movies, TV shows, game/toys, etc.) may have had on interest in STEM. Lastly, we designed one question to test the dynamics between female/male students and their female/male professors.

\section{Method Justification}

We used an online survey for our research since it allowed us to reach a higher number of respondents. Although surveys can limit the amount of information given by respondents and sometimes provide inaccurate data, due to our limited time, it seemed like the best approach to gather reliable information in a timely manner. Taking into consideration that the design of our survey could prime our respondents and affect their responses, we hoped that the anonymity of the survey would instigate them to provide a more candid and valid response; thus, allowing us to identify a more generalized and representative understanding of some of the perceived factors that lead men and women into studying STEM. Given its online format, we were able to target a larger sample and distribute the survey more efficiently without any cost.

\section{Population and Survey Distribution}

The survey targeted both female and male undergraduate STEM students at Columbia University, including Columbia College, Barnard College, the School of General Studies and the School of Engineering and Applied Science. Our aim was to reach students from various levels of academic standing and different backgrounds.

We distributed our survey through various channels. We first shared the survey through social media (i.e. Facebook); we asked STEM professors from the Division of Natural Sciences, the School of Engineering and Applied Science, and the Columbia University Medical Center to help distribute our survey to their students; and we also contacted and physically visited several STEM clubs run by students, including women's clubs such as WICS (Women in Computer Science) and Society of Women Engineers.

\section{Survey Question Format}

1. Multiple choice / single answer 
2. Multiple choice / multiple answer

3. Ranking single statement (scale -5 to +5 , strongly disagree to strongly agree)

4. Ranking multiple items (sum $=100 \%)$

5. Open-ended questions

\section{Question Design / Data Collected}

As mentioned above, the survey questions focus mainly on two perspectives: perceived individual and social factors. To measure the weight of these factors, all answers are evaluated on a -5 (extremely negative) to 5 (extremely positive) scale.

\section{- Perceived Individual Factors}

Questions on individual factors include: respondents' personality traits, changes in their interest and performance in STEM, and their career orientation at primary school, high school, and college. For the personality traits question, we used a ranking format for multiple items (sum=100\%). Our intent was to induce our respondents into a trade-off among the three options given. This question was designed to assess whether or not gender-specific preferences emerged and which of these best represented men and women. The questions covered their preference in:

- their approach to understanding (Observe, Think, Do)

- their role while solving a problem in a group (Plan, Implement, Lead)

- their motivation to solve a problem (Challenge oneself, Compete with others, Find solutions).

A sample of these questions is shown in Figure 1.

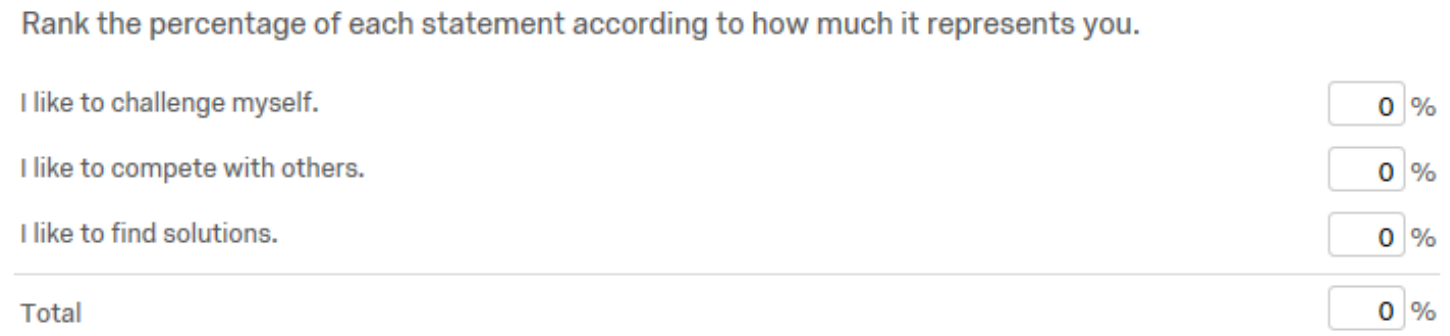

Fig. 1 Sample personality traits question

To assess if there were any changes in perceived interest and performance in STEM over time, we asked our respondents to answer on a scale of [-5;5] their level of interest and achievement. We selected the most relevant course related to STEM for each stage while providing them with an option to report two additional courses in which they may have been interested (i.e. Mathematics for primary school, Mathematics and two other preferred courses for high school, and Calculus and two other preferred courses for college). The option for two other preferred courses was included in order to enable us to measure the range of respondents' interests. A sample of these questions is shown in 
Figure 2:

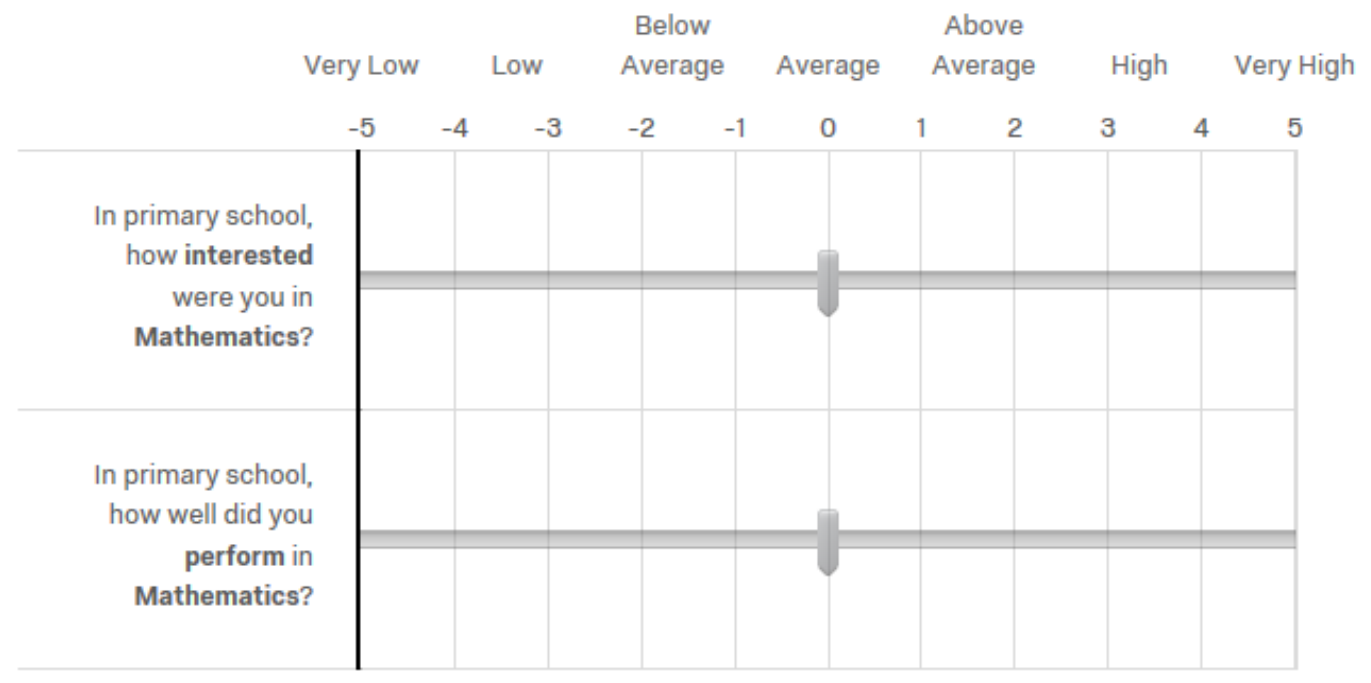

Fig. 2 Sample interest / performance question in primary school

\section{- Perceived Social Factors}

For social factors, we looked at four primary agents of socialization - family, school, peer groups, and mass media. We also looked for perceived community integrations within their field and any other type of community association. For each of the three life stages, we adapted the socialization agents to address the specificity of each time period. For instance, while parents and siblings/relatives were consistent in all stages, for primary school, respondents were asked about a significant teacher; in high school, they were asked about a significant teacher and their mathematics teacher; at college, they were asked about two significant professors, one teaching assistant, and any tutor that may have influenced their interest in STEM. A sample of these questions is shown in Figure 3:

\begin{tabular}{|c|c|c|c|c|c|c|c|c|c|c|c|c|c|c|c|}
\hline & \multirow[b]{2}{*}{$\begin{array}{l}\text { Relationship to you /What } \\
\text { course s/he taught }\end{array}$} & \multirow[b]{2}{*}{ Male } & \multirow[b]{2}{*}{ Female } & \multicolumn{12}{|c|}{$\begin{array}{l}\text { Contribution to your interest in Science } \\
\begin{array}{c}-5=\text { strongly discouraging } \\
5=\text { strongly encouraging } \\
\text { N/A }=\text { Not Applicable }\end{array}\end{array}$} \\
\hline & & & & -5 & -4 & -3 & -2 & -1 & 0 & 1 & 2 & 3 & 4 & 5 & N/A \\
\hline Father/Male Guardian/Significant Adult & $\ldots$ & $\bullet$ & 0 & 0 & O & $\bigcirc$ & O & 0 & 0 & 0 & 0 & 0 & $\bigcirc$ & O & O \\
\hline Mother/Female Guardian/Significant Adult & $-\cdots-{ }_{n}$ & 0 & $\bullet$ & O & O & 0 & 0 & 0 & 0 & 0 & 0 & 0 & ○ & O & 0 \\
\hline Sibling / Relative (please specify) & & O & ○ & 0 & ○ & 0 & ○ & O & 0 & 0 & 0 & ○ & $\bigcirc$ & O & 0 \\
\hline High School Mathematics Teacher & $-\cdots-x_{1}$ & ○ & O & 0 & O & 0 & 0 & 0 & 0 & 0 & 0 & 0 & 0 & 0 & 0 \\
\hline Other Significant Teacher (please specify) & & O & O & O & ○ & $\bigcirc$ & 0 & 0 & 0 & 0 & $\bigcirc$ & O & 0 & 0 & 0 \\
\hline High School Close Friend \#1 & $-\cdots$ & ○ & O & 0 & ○ & 0 & 0 & $\bigcirc$ & 0 & 0 & 0 & 0 & $\bigcirc$ & 0 & 0 \\
\hline High School Close Friend \#2 & $-\cdots-n_{1}$ & 0 & 0 & O & ○ & 0 & O & ○ & O & 0 & 0 & O & ○ & O & O \\
\hline High School Close Friend \#3 & ----- & 0 & 0 & 0 & 0 & 0 & 0 & 0 & 0 & 0 & 0 & 0 & 0 & 0 & 0 \\
\hline
\end{tabular}

Fig. 3 Sample family, teacher, peer influence question in high school 
Our hypothesis was that the closer the tie, the higher would be their level of perceived influence. Hence, for students in primary school, the parents would play the most significant role; for students in high school, peer influence would be the most salient; whereas at college, peers and teachers would present a higher level of influence.

In terms of mass media, questions were asked to measure the extent of perceived influence from public figures and items (i.e. books, movies, TV shows, games/toys, etc.) on our respondents' interest in STEM.

We also measured the perceived community integration of our respondents by dividing it into three levels of analysis. First, we asked our respondent to self-assess their integration as it relates to their field using a scale of $[-5 ; 5]$. This question is shown in Figure 4:

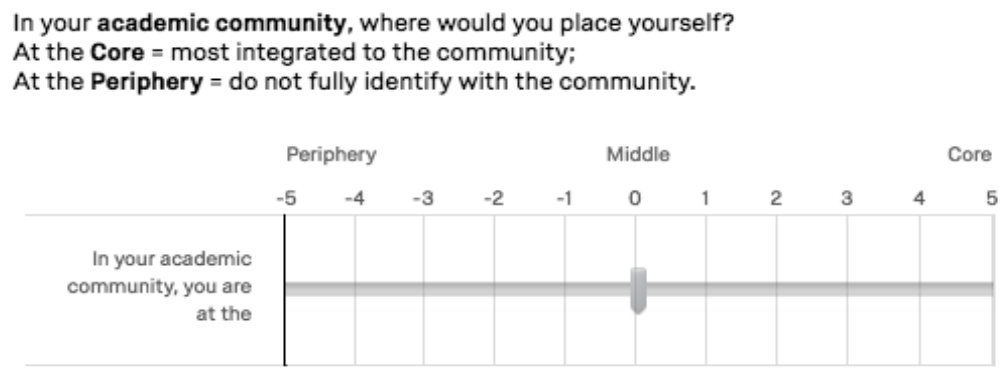

Fig. 4 Sample academic STEM community integration question at college

The second level addressed perceived STEM integration of our respondents by collecting self-reported membership in STEM club associations and study groups on a scale of [-5;5]. This approach was used as a way to measure the need of our respondents for social support. The third level rested in conducting interviews, asking 7 respondents about any other individual with whom each respondent may spend time and talk to about STEM. This third level allowed us to build ego-networks, in which the respondent as a node is tied to all of the individuals mentioned by the respondent. The intent was to assess the gender distribution of the STEM network of each respondent. Lastly, we assessed the dynamics between our respondents and their professors. In this question respondents were asked to answer how they would respond to a professor who arbitrarily rejects their way of solving a problem. The survey system randomly assigned the gender of the professor in the question so that half of the respondents were prompted to respond to a male professor and the other half had to respond to a female one. The survey provided six different responses to this randomized question- three of which provided different levels of confrontation whereas the other three provided alternatives where confrontation would be prevented. This question is meant to assess the respondent's perception of authority as it relates to gender. The two versions of this question are shown in Figure 5: 


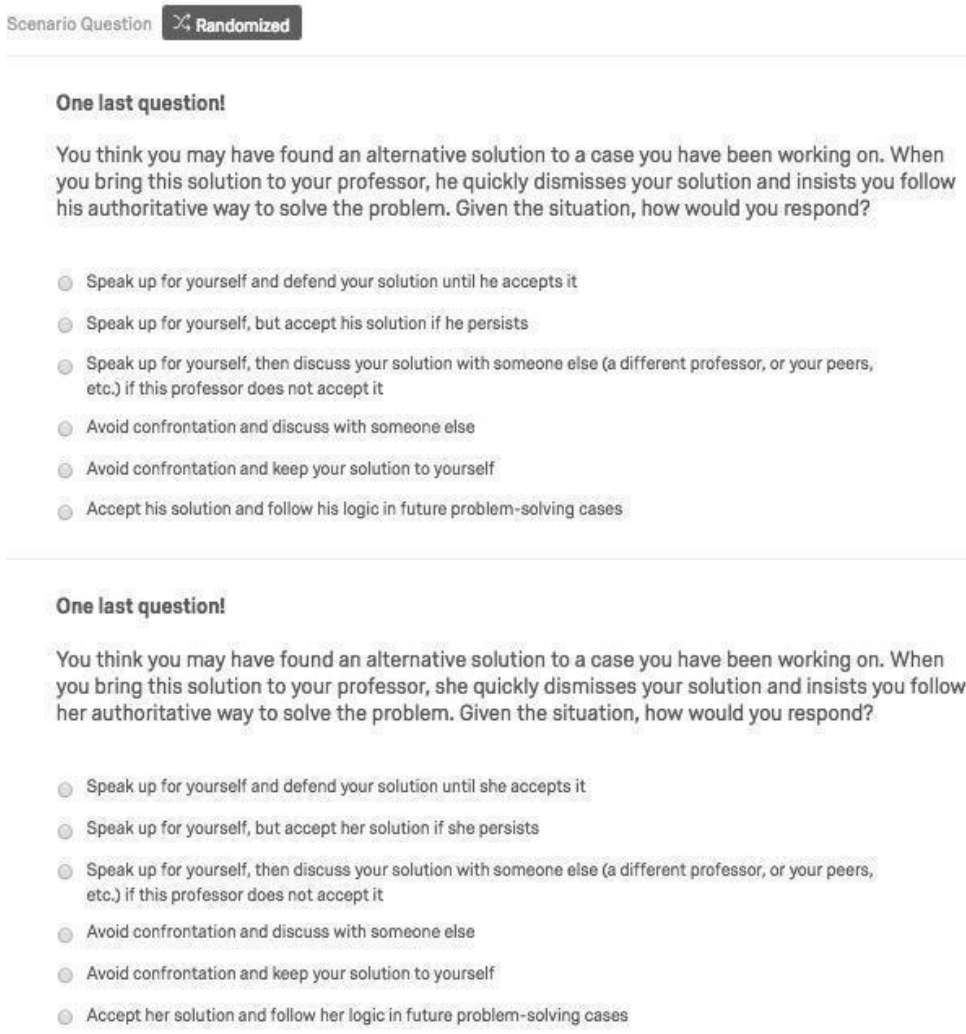

Fig. 5 Sample respondent-professor dynamics question at college

\section{Results}

By the time we closed our survey, we had received a total of 64 responses, out of which 29 were females and 35 were males. Figure 6 breaks down our respondents according to their gender while Figure 7 provides the breakdown of our respondents according to their major. To identify the presence or absence of significant difference between women and men when it comes to their perceived individual preferences and social environment, we used statistical tests in which we set the statistical significance level at $\mathrm{p}$-value $<0.05$. 


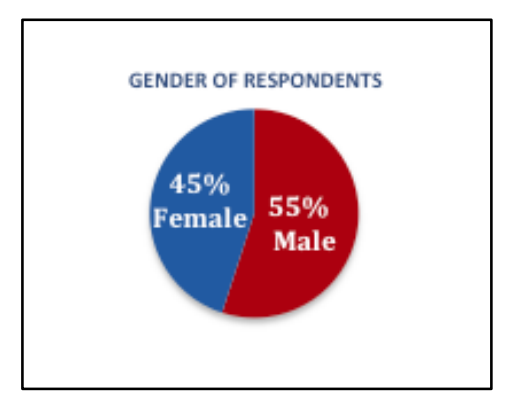

Fig. 6 Gender distribution of respondents

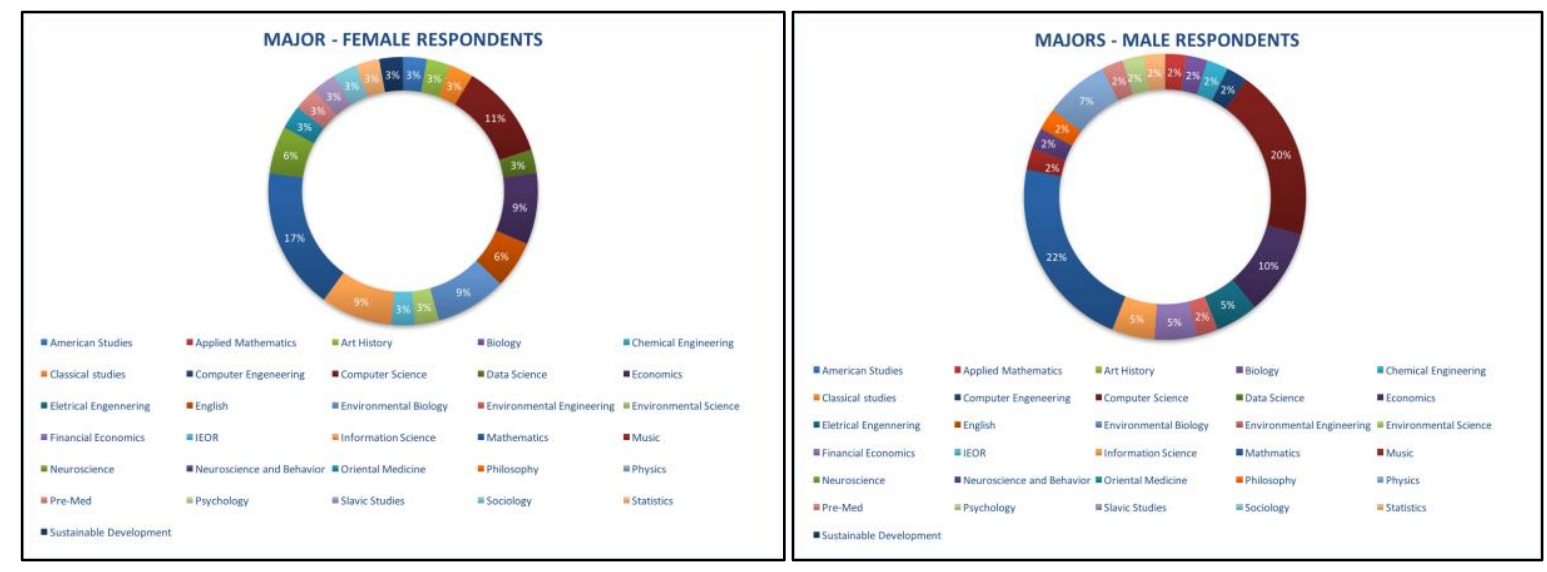

Fig. 7 Major distribution of respondents

\section{- Perceived Individual Factors}

\section{○ Hypothesis 1: Perceived Personality Traits Do Not Differ by Gender}

We anticipated that by similarly choosing a STEM education, STEM female and male students would share enough perceived personality traits to the extent that these would not drastically differ by gender.

Although we did not specifically ask for religious affiliation, we did measure the level of religiosity of our respondents. They were asked to report their religious inclination on a scale of -5 (materialistic) to 5 (religious). Even though the results show that women (0.68) are on average more religious than men $(0.21)$, using a t-test, there is no statistically significant difference between women and men in terms of religious inclination $(\mathrm{p}<0.05)$. Similarly, there is no statistically significant difference at the $\mathrm{p}<0.05$ level between female $(-0.28)$ and male (1.71) respondents in the way they perceive science problems. Figure 8 shows this average survey answer by gender: 


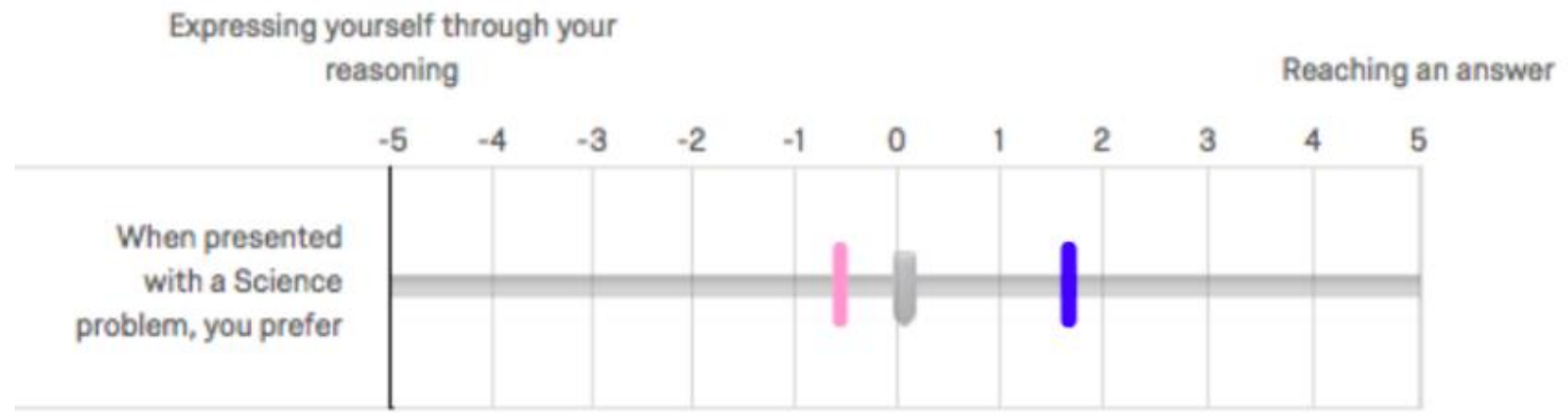

Fig. 8 Average perception of scientific problem (scaled from -5 to +5 , female student as pink and male student as blue)

For the questions involving a trade-off among three options (i.e., Planner/Leader/Implementer, Thinker/Doer/Observer, and Challenge Myself/Compete with Others/Find Solutions), we analyzed the personality traits answers by plotting them into 3 triangles and dividing each triangle into six regions (i.e., six smaller triangles marked with different colors in Figures 9, 10 and 11). We then calculated the sum of women and men present in each of the three main personality traits regions, for each of the three triangles (Figures 9, 10 and 11). When a respondent reported 50\% for two personality traits placing him/herself on a black line of the triangle - we counted the survey answer as 0.5 for each of the two personality traits regions divided by that line. If a respondent reported $33.3 \%$ for each of the three personality traits - placing him/herself at the orthocenter of the triangle - we counted the survey answer as 0.17 for each of the six personality traits regions.

Using the Chi-squared test of no relationship between gender and personality traits, there is not enough evidence to reject the null hypothesis. Therefore, there is no statistically significant difference between women and men in terms of the given personality traits at the $p<0.05$ level. This result confirms our hypothesis that there is no statistically significant gender difference among STEM students in terms of the three tested perceived personality traits. However, our selective sampling cannot answer whether there are differences between STEM and non-STEM students, or between women and men in general. 


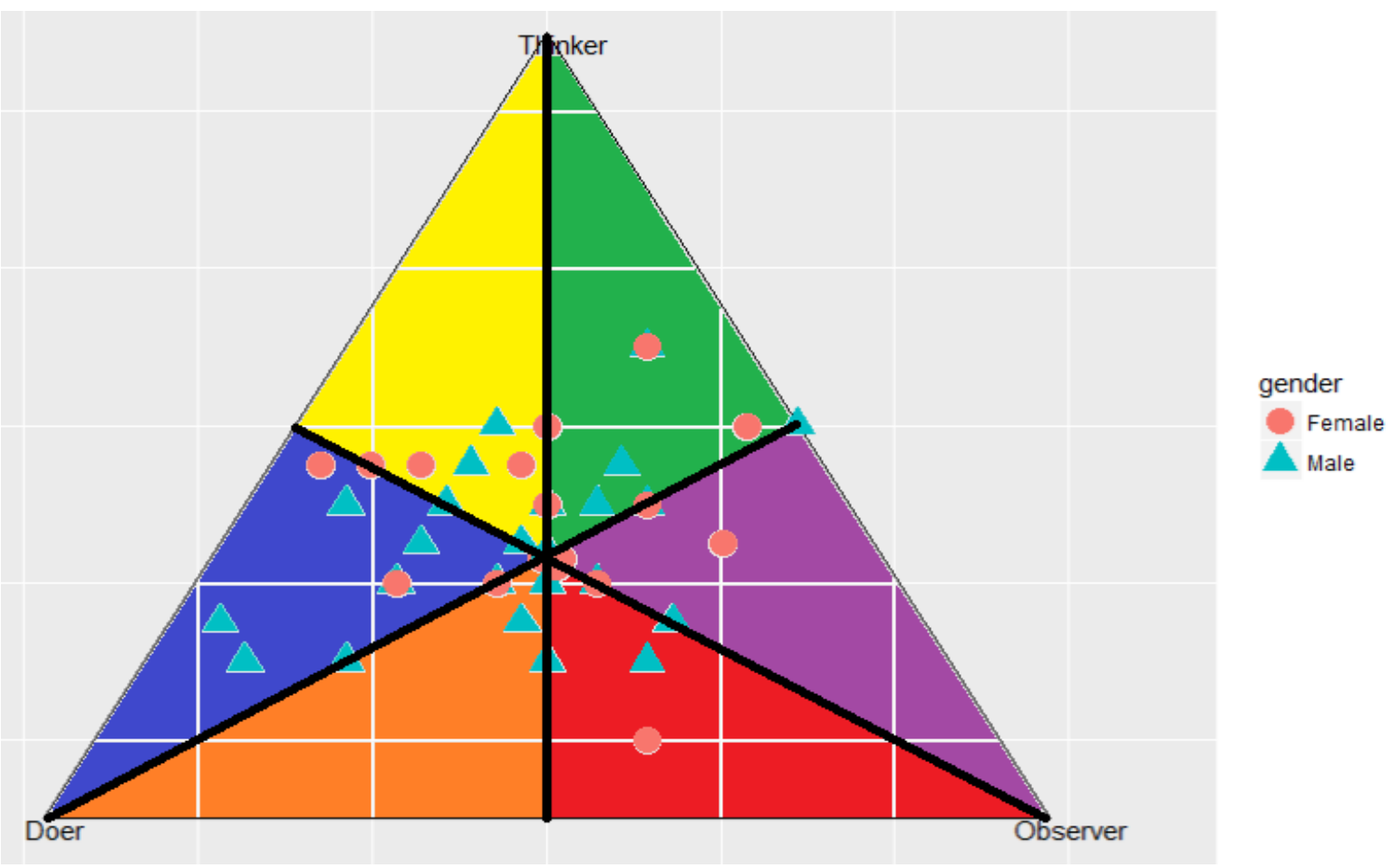

Fig. 9 Personality trait by gender: thinker/doer/observer

Relationship between Gender and Personality Trait (Thinker/Doer/Observer) Coded as Colored Region

\begin{tabular}{|c|c|c|c|c|c|c|c|c|}
\hline \multirow{4}{*}{$\begin{array}{l}\text { Observed } \\
\text { Number of } \\
\text { Respondents }\end{array}$} & & Red & Purple & Green & Yellow & Blue & Orange & Total \\
\hline & Female & 3.7 & 4.2 & 7.7 & 5.7 & 5.2 & 1.7 & 28 \\
\hline & Male & 4.7 & 4.2 & 7.7 & 5.2 & 8.2 & 4.2 & 34 \\
\hline & Total & 8.3 & 8.3 & 15.3 & 10.8 & 13.3 & 5.8 & 62 \\
\hline \multirow{4}{*}{$\begin{array}{l}\text { Expected } \\
\text { Number of } \\
\text { Respondents }\end{array}$} & & Red & Purple & Green & Yellow & Blue & Orange & Total \\
\hline & Female & 3.8 & 3.8 & 6.9 & 4.9 & 6 & 2.6 & 28 \\
\hline & Male & 4.6 & 4.6 & 8.4 & 5.9 & 7.3 & 3.2 & 34 \\
\hline & Total & 8.3 & 8.3 & 15.3 & 10.8 & 13.3 & 5.8 & 62 \\
\hline
\end{tabular}

Table 1 Number of respondents per personality trait region by gender: thinker/doer/observer*

*Please refer to the above textual analysis for details on the counting methodology 


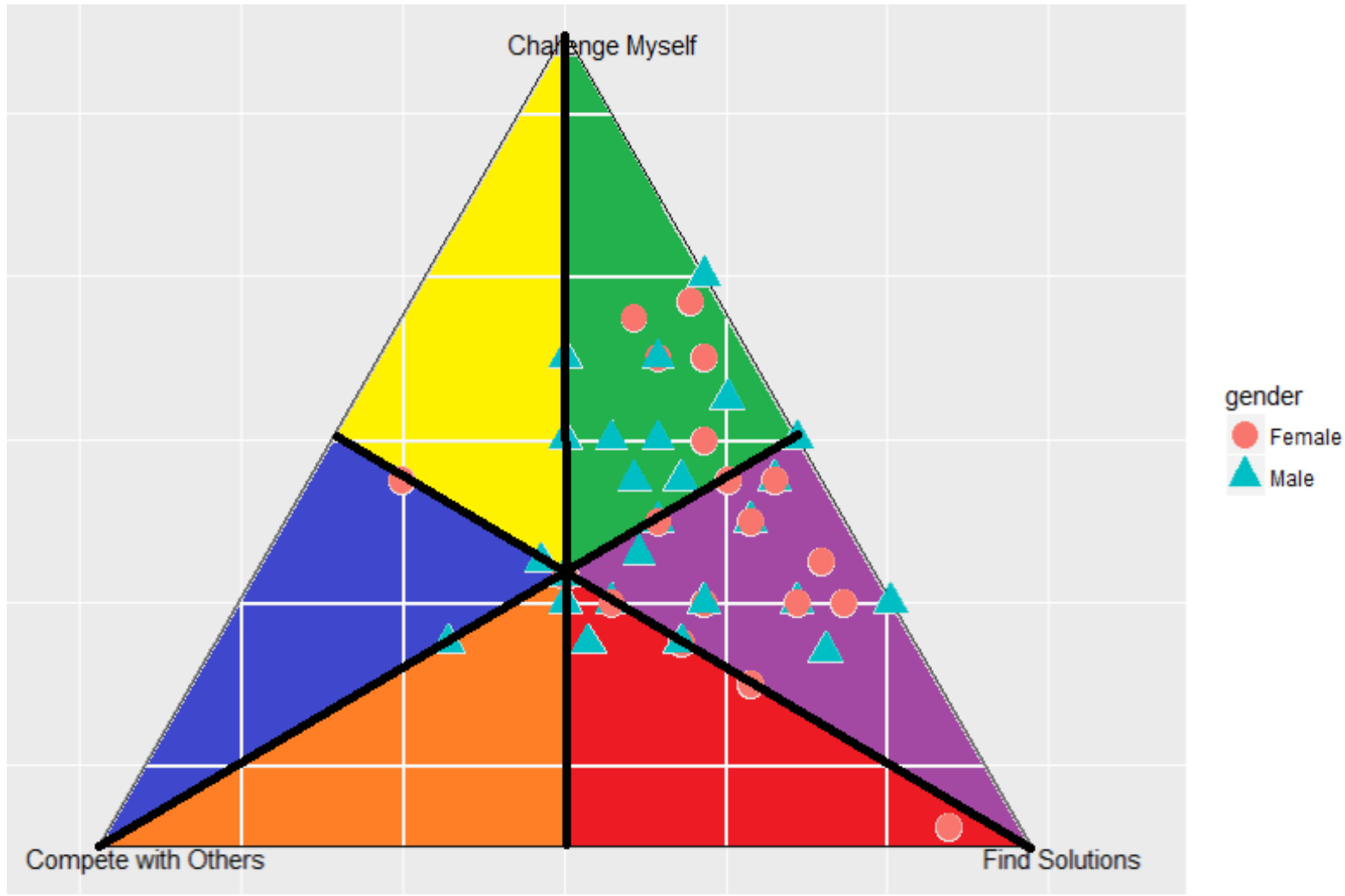

Fig. 10 Personality trait by gender: challenge oneself/compete/find solutions

Relationship between Gender and Personality Trait (Challenge Myself/Compete with Others/Find Solutions) Coded as Colored Region

\begin{tabular}{|c|c|c|c|c|c|c|c|c|}
\hline \multirow{4}{*}{$\begin{array}{l}\text { Observed } \\
\text { Number of } \\
\text { Respondents }\end{array}$} & & Red & Purple & Green & Yellow & Blue & Orange & Total \\
\hline & Female & 3.8 & 12.8 & 9.3 & 0.8 & 0.8 & 0.3 & 28 \\
\hline & Male & 3.5 & 12.5 & 13 & 2 & 1.5 & 1.5 & 34 \\
\hline & Total & 7.3 & 25.3 & 22.3 & 2.8 & 2.3 & 1.8 & 62 \\
\hline \multirow{3}{*}{$\begin{array}{l}\text { Expected } \\
\text { Number of } \\
\text { Respondents }\end{array}$} & Female & 3.3 & 11.4 & 10.1 & 1.3 & 1.1 & 0.8 & 28 \\
\hline & Male & 4 & 13.9 & 12.2 & 1.6 & 1.3 & 1 & 34 \\
\hline & Total & 7.3 & 25.3 & 22.3 & 2.8 & 2.3 & 1.8 & 62 \\
\hline
\end{tabular}

Table 2 Number of respondents per personality trait region by gender: challenge oneself/compete/find solutions 


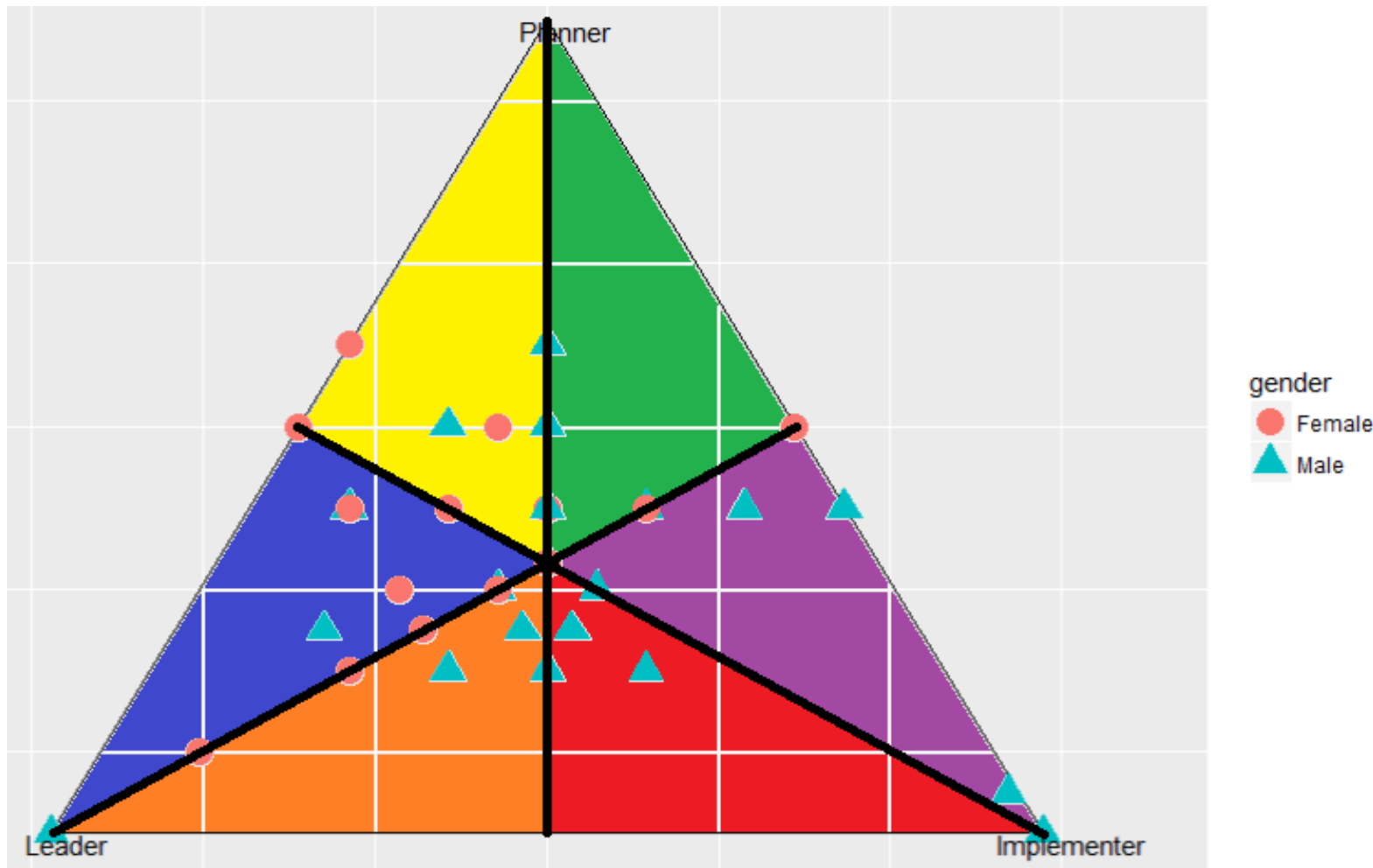

Fig. 11 Personality trait by gender: planner/leader/implementer

Relationship between Gender and Personality Trait (Planner/Leader/Implementer) Coded as Colored Region

\begin{tabular}{|c|c|c|c|c|c|c|c|c|}
\hline \multirow{4}{*}{$\begin{array}{l}\text { Observed } \\
\text { Number of } \\
\text { Respondents }\end{array}$} & & Red & Purple & Green & Yellow & Blue & Orange & Total \\
\hline & Female & 0.3 & 1.8 & 2.3 & 4.8 & 5.8 & 2.8 & 18 \\
\hline & Male & 5.7 & 4.7 & 2.2 & 2.7 & 4.2 & 3.7 & 23 \\
\hline & Total & 6 & 6.5 & 4.5 & 7.5 & 10 & 6.5 & 41 \\
\hline \multirow{4}{*}{$\begin{array}{l}\text { Expected } \\
\text { Number of } \\
\text { Respondents }\end{array}$} & & Red & Purple & Green & Yellow & Blue & Orange & Total \\
\hline & Female & 2.6 & 2.9 & 2 & 3.3 & 4.4 & 2.9 & 18 \\
\hline & Male & 3.4 & 3.6 & 2.5 & 4.2 & 5.6 & 3.6 & 23 \\
\hline & Total & 6 & 6.5 & 4.5 & 7.5 & 10 & 6.5 & 41 \\
\hline
\end{tabular}

Table 3 Number of respondents per personality trait region by gender: planner/leader/implementer 


\section{- Hypothesis 2: Perceived Interest and Performance in Mathematics Do Not Differ by Gender}

We assumed that there should be no large difference in the perceived interest in mathematics between STEM women and STEM men, although statistically-speaking, American men and women still show moderate to minor difference in their interest in mathematics nowadays. However, much to our surprise, given the self-reported interest in mathematics shown in Figure 12, women respondents seem to be on average much less interested in mathematics than men respondents in primary school. Given a -5 to 5 scale, women and men self-reported an average of 0.0 and 2.5 respectively. Considering a t-test, there is a statistically significant difference between women and men in terms of self-reported interest in mathematics at the $\mathrm{p}<0.05$ level.

When it comes to self-reported performance in mathematics, a t-test shows that there exists a statistically significant difference at the $\mathrm{p}<0.05$ level between men and women as men report that they performed much better than women perceive they did in primary school. In other words, if the actual performance of these men and women were about the same level (which, unfortunately, cannot be proved), women underestimate their performance compared to their male peers. So far, the results are consistent with current literature which has pointed out that women show less self-confidence in selfassessments, interest, or motivation in STEM (Ceci et al. 2009; Correll 2001; Xie et al. 2015).

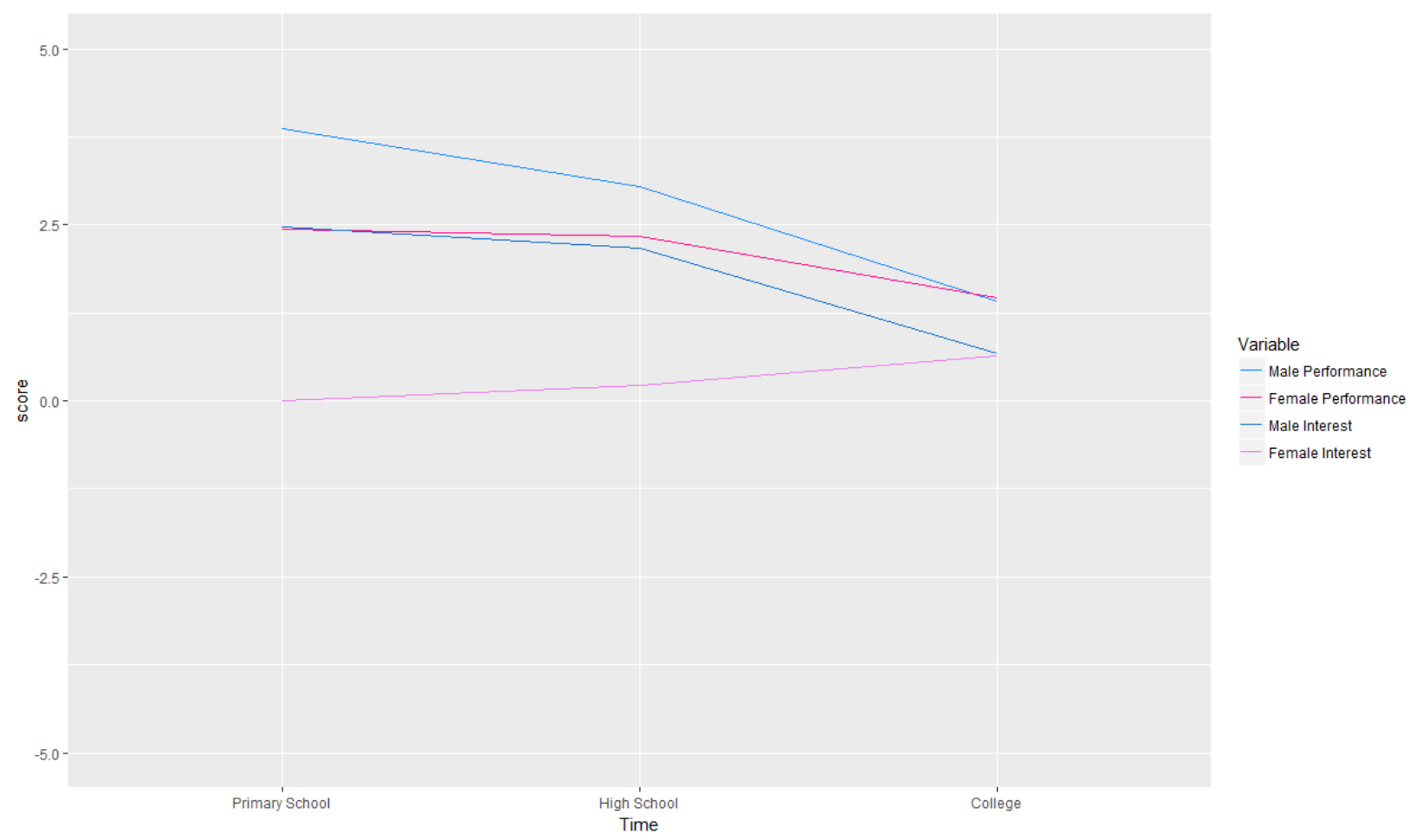

Fig. 12 Average female and male scores of interest and perceived performance in mathematics over time

(scaled from -5 to +5$)$ 


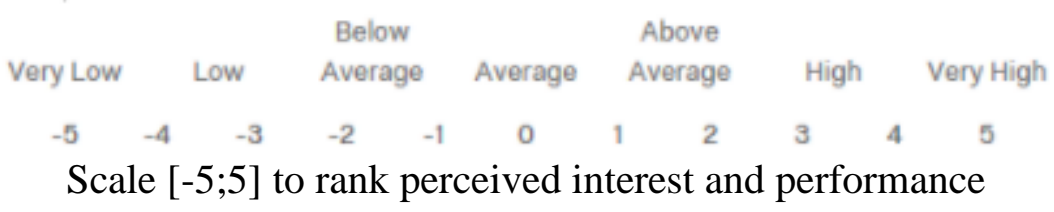

For both women and men, the gap between perceived interest and performance in mathematics decreases in high school and disappears completely at college. Using a t-test, we found that women and men have a statistically significant difference in interest in STEM during high school at the $p<0.05$ level. However, their perceived performance in STEM during high school is not significantly different at the $p<0.05$ level. As shown in Figure 12, both the interest and performance lines converge during college. Figure 12 helps us understand not only statistically significant differences between women and men, but also increase and decline in interest and performance over time by gender.

From primary school to college, both women and men reported a decline in their mathematics performance and this decline eventually converges to the same perceived level of performance at college. More interestingly, women's interest in mathematics increases as they grow older; in fact, it is the only line of the four shown in Figure 12 that increases over time. On the other hand, men's interest in mathematics decreases over time, which challenges the common understanding that women are less likely than men to be recruited into STEM due to their lack of interest in the field, as indicated in Legewie and Diprete's article "Pathways to science and engineering bachelor's degrees for men and women" (Legewie and DiPrete 2014). Although not proven, such inconsistency is very likely due to a generational difference given that Legewie et al.'s subjects belong to the 1973-1974 birth cohort.

Although female interest in mathematics increases over time, their perceived performance in mathematics declines; for male students, both their perceived interest and performance in mathematics decline over time. This different evolution of interest over time for women and men who study STEM at college may indicate that interest plays a more important role for women than for men in the decision to pursue a STEM education.

Instead of investigating what makes women decide not to pursue STEM, we can also question what makes men disproportionally select STEM while both their interest and performance decline over time. One hypothesis is that men could be under larger social or cultural pressure than women to pursue financially stable, and therefore technical, careers. Specifically, men may perceive greater expectation and responsibility, which is also supported by other findings from our survey, with men placing a larger weight on income than women, as shown in Figure 13. In turn, women may tend to focus more on their contribution to society at large than men do, when considering future career choices. Figure 13 shows the level of importance the average man and woman STEM college student attach to the given set of criteria in making their career choice. All numerical weights attached to each criteria had to sum to a hundred. 


\begin{tabular}{|c|c|c|}
\hline Field & Mean & Mean \\
\hline Accessibility to the industry through your connections & 5.25 & 5.58 \\
\hline Possibility for professional growth & 16.71 & 15.00 \\
\hline Income & 22.63 & 16.50 \\
\hline Work-life balance & 17.54 & 17.13 \\
\hline Work environment & 16.83 & 17.00 \\
\hline Contribution to Society at large & 17.42 & 24.25 \\
\hline Parents' expectation & 3.63 & 4.55 \\
\hline
\end{tabular}

Fig. 13 Average percentage of importance attributed to each criteria (field) in choosing a career; for men (first column) and women (second column)

\section{- Perceived Social Factors}

\section{○ Hypothesis 3: Perceived Local Networks (Family, School, Peer Influence) Differ by Gender}

We assumed that women need more support and encouragement than men from their local networks in order to choose a STEM education, and the findings do not reject overall our hypothesis. Figure 14 shows the average women and men's local network in primary school and the average STEM support they feel they received from family members, teachers and friends respectively, where a green line means positive influence (encouragement) while a red line means negative influence (discouragement), and the thickness of the line indicates the magnitude of the influence. 

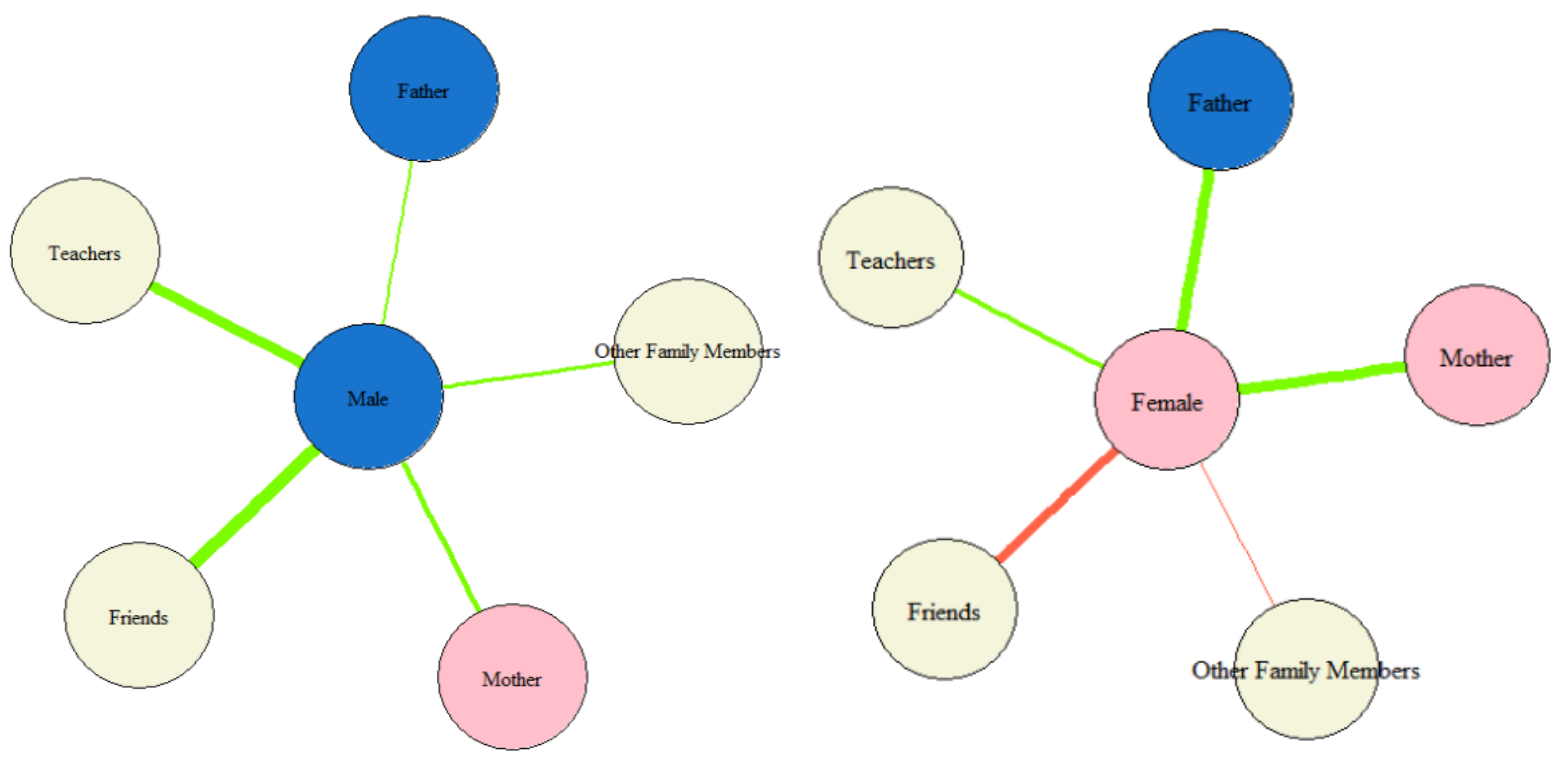

Fig. 14 Average local network in primary school by gender

\begin{tabular}{|c|c|c|c|c|c|c|c|}
\hline \multicolumn{8}{|c|}{ Relationship between Gender and Average STEM Support in Primary School } \\
\hline \multirow{4}{*}{$\begin{array}{l}\text { Observed } \\
\text { Average } \\
\text { Support }\end{array}$} & & Father & Mother & Other Family Members & Teachers & Friends & Total \\
\hline & Female & 1.4 & 1.5 & -0.2 & 0.7 & -1.4 & 2.1 \\
\hline & Male & 0.4 & 0.8 & 0.7 & 1.8 & 2 & 5.8 \\
\hline & Total & 1.9 & 2.3 & 0.5 & 2.5 & 0.6 & 7.8 \\
\hline \multirow{4}{*}{$\begin{array}{l}\text { Expected } \\
\text { Average } \\
\text { Support }\end{array}$} & & Father & Mother & Other Family Members & Teachers & Friends & Total \\
\hline & Female & 0.5 & 0.6 & 0.1 & 0.7 & 0.2 & 2.1 \\
\hline & Male & 1.4 & 1.7 & 0.4 & 1.8 & 0.5 & 5.8 \\
\hline & Total & 1.9 & 2.3 & 0.5 & 2.5 & 0.6 & 7.8 \\
\hline p-value & $6.0 \mathrm{E}-05$ & & & & & & \\
\hline
\end{tabular}

Table 4 Average support from social actors in primary school by gender (scaled from -5 to 5 )

Considering the Chi-squared test of no relationship between gender and average support from social actors in primary school, women report significantly less support from their close network than men do at the $\mathrm{p}<0.05$ level, as shown in Table 4 . Women feel on average negatively influenced, discouraging their interest in STEM, by their friends and other family members while men seem to receive more support from teachers and friends, i.e., people outside the family rather than from within the family. The support women do receive seems to come on average from their parents. This can be explained by socialization theories: since boys receive more general support from society at large, parents' influence are not so salient or important to encourage them to study STEM; in contrast, because girls lack this kind of general support, encouragement and strong support from their parents play a crucial role in their decision to pursue a STEM education. In other words, when parents are only moderately supportive of their child's STEM orientation, boys are more likely than girls to choose to pursue a STEM education. 
Figure 15 indicates that in high school, considered the life stage when peer influence is most significant, the average woman feels much more support from her friends than men do. The dynamics have therefore changed compared to primary school. In fact, not a single male respondent in our survey reports any peer influence at this stage - considering the fact that many do report peer influence in the other two life stages, we consider this no-response as the absence of a salient influence worth reporting. Using the Chi-squared test of no relationship between gender and average support from social actors in high school, there is no statistically significant difference in the self-reported support between women and men at the $\mathrm{p}<0.05$ level, as shown in Table 5.
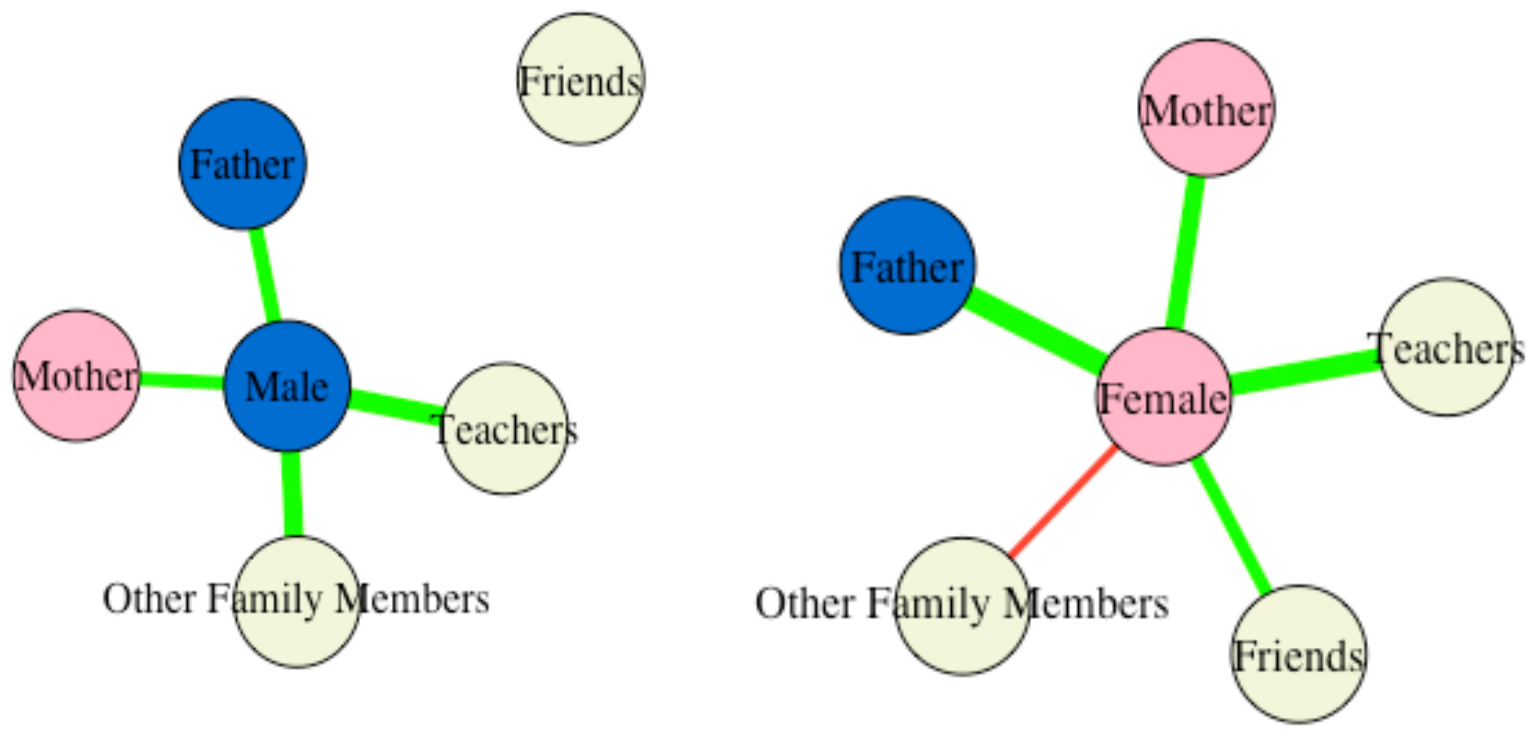

Fig. 15 Average local network in high school by gender

\begin{tabular}{|c|c|c|c|c|c|c|c|}
\hline \multicolumn{8}{|c|}{ Relationship between Gender and Average STEM Support in High School } \\
\hline \multirow{4}{*}{$\begin{array}{l}\text { Observed } \\
\text { Average } \\
\text { Support }\end{array}$} & & Father & Mother & Other Family Members & Teachers & Friends & Total \\
\hline & Female & 1.8 & 1.4 & -0.6 & 1.6 & 1 & 5.2 \\
\hline & Male & 1.2 & 1.1 & 1.5 & 1.6 & 0 & 5.4 \\
\hline & Total & 3 & 2.5 & 0.9 & 3.2 & 1 & 11 \\
\hline \multirow{4}{*}{$\begin{array}{l}\text { Expected } \\
\text { Average } \\
\text { Support }\end{array}$} & & Father & Mother & Other Family Members & Teachers & Friends & Total \\
\hline & Female & 1.5 & 1.2 & 0.4 & 1.6 & 0.5 & 5.2 \\
\hline & Male & 1.5 & 1.2 & 0.5 & 1.6 & 0.5 & 5.3 \\
\hline & Total & 3 & 2.4 & 0.9 & 3.2 & 1 & 11 \\
\hline p-value & 0.23 & & & & & & \\
\hline
\end{tabular}

Table 5 Average support from social actors in high school by gender (scaled from -5 to 5 )

Finally, at college, Figure 16 indicates that both women and men STEM students feel on average similarly strong support from their professors and peers. Professors and peers, who constitute during college a respondent's closest network if the respondent lives far from home, seem to play a significant role in shaping a respondent's orientation towards STEM. Nonetheless, other family members such as siblings and uncles remain for men a strong source of support, despite any potential physical distance. 
Furthermore, while not a single male respondent in our survey reported any teaching assistant's (TA) influence at college, women indicated a moderate influence of their TAs on their orientation towards STEM. These findings seem to show that again, because women lack a general STEM support, encouragement and strong support from their local college network, mainly TAs, can make a difference in their decision to persist in studying STEM. Considering the Chi-squared test of no relationship between gender and average support from social actors at college, there is nonetheless no statistically significant difference in the self-reported support between women and men at the $p<0.05$ level, as shown in Table 6.
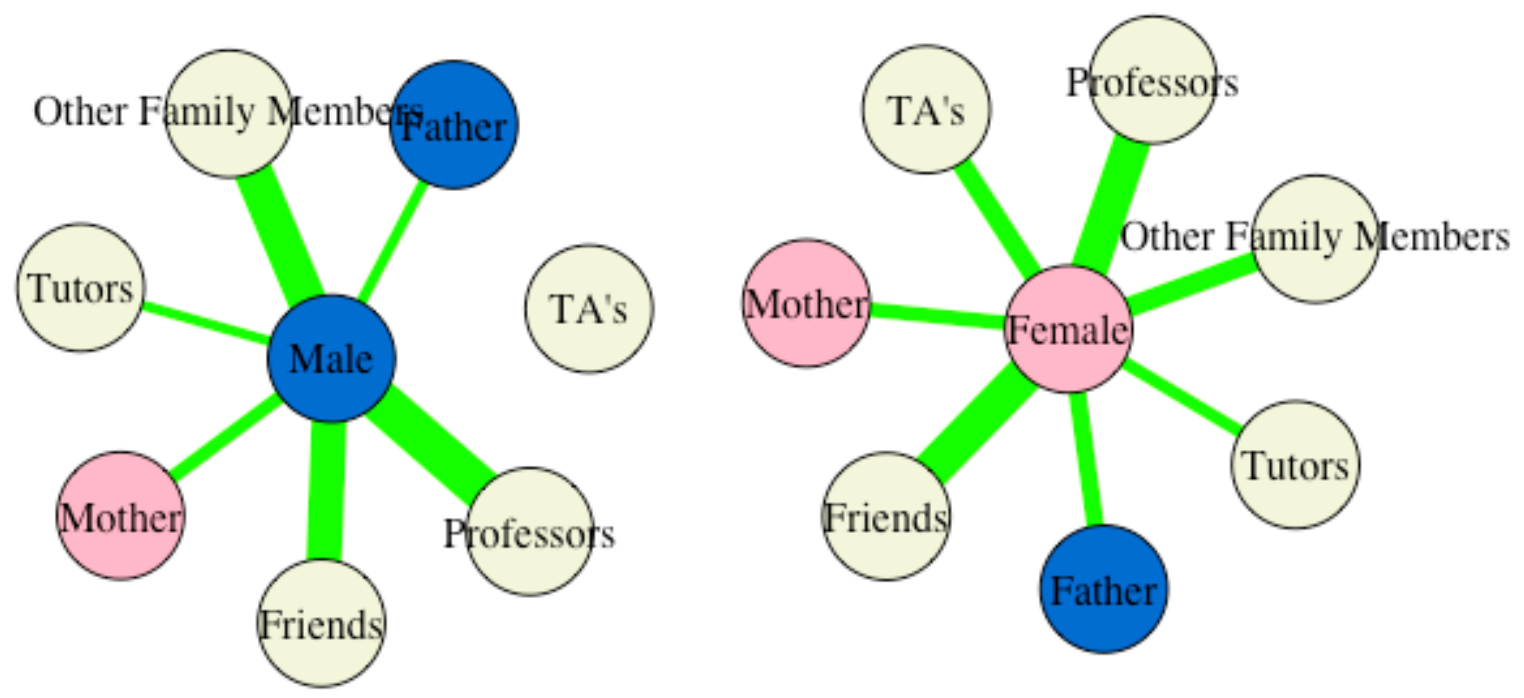

Fig. 16 Average local network at college by gender

\begin{tabular}{|c|c|c|c|c|c|c|c|c|c|}
\hline \multicolumn{10}{|c|}{ Relationship between Gender and Average STEM Support at College } \\
\hline \multirow{4}{*}{$\begin{array}{l}\text { Observed } \\
\text { Average } \\
\text { Support }\end{array}$} & & Father & Mother & Other Family Members & Professors & Teaching Assistants & Tutors & Friends & Total \\
\hline & Female & 1.4 & 1.1 & 1.6 & 2.9 & 1.6 & 1 & 3 & 13 \\
\hline & Male & 0.9 & 1.1 & 3 & 3.3 & 0 & 0.8 & 2.7 & 12 \\
\hline & Total & 2.3 & 2.2 & 4.6 & 6.2 & 1.6 & 1.8 & 5.7 & 24 \\
\hline \multirow{4}{*}{$\begin{array}{l}\text { Expected } \\
\text { Average } \\
\text { Support }\end{array}$} & & Father & Mother & Other Family Members & Professors & Teaching Assistants & Tutors & Friends & Total \\
\hline & Female & 1.1 & 1.1 & 2.4 & 3.2 & 0.8 & 0.9 & 3 & 13 \\
\hline & Male & 1.1 & 1.1 & 2.2 & 3 & 0.8 & 0.9 & 2.8 & 12 \\
\hline & Total & 2.2 & 2.2 & 4.6 & 6.2 & 1.6 & 1.8 & 5.8 & 24 \\
\hline p-value & 0.88 & & & & & & & & \\
\hline
\end{tabular}

Table 6 Average support from social actors at college by gender (scaled from -5 to 5 )

The overarching findings from the local networks at these three different life stages show that women are in greater need of local support than men in the process of choosing to study STEM, especially during primary school. 


\section{○ Hypothesis 4: College Club Membership Differs by Gender}

Just as for Hypothesis 3, we assumed that women need more support and encouragement than men from their local network in order to choose a STEM education. Therefore, we anticipated club membership to differ by gender. We found evidence of such disparity in terms of club affiliation, but not in terms of type of club affiliation (STEM versus non-STEM).

Figure 17 visualizes whether women and men are affiliated to academic clubs on campus, and if so, whether those clubs are related to STEM (STEM clubs are shown in yellow, while non-STEM clubs are shown in beige). No significant difference at the $\mathrm{p}<0.05$ level between women and men has been found between STEM and non-STEM club affiliation as shown in the Chi-squared test in Table 7.2. Nonetheless, a significant difference at the $\mathrm{p}<0.05$ level is observed in relation to gender regarding an overall club membership as reported in Table 7.1. Table 7.2 indicates that women have more ties than men not only to STEM (14 versus 5 ties) but also non-STEM clubs (29 versus 20 ties). This finding shows that women may seem to need more social support than men at college. Supporting this finding is the existence of STEM women-only clubs such as "Women in Computer Science" and "Society of Women Engineers" while their male equivalent remains inexistent.

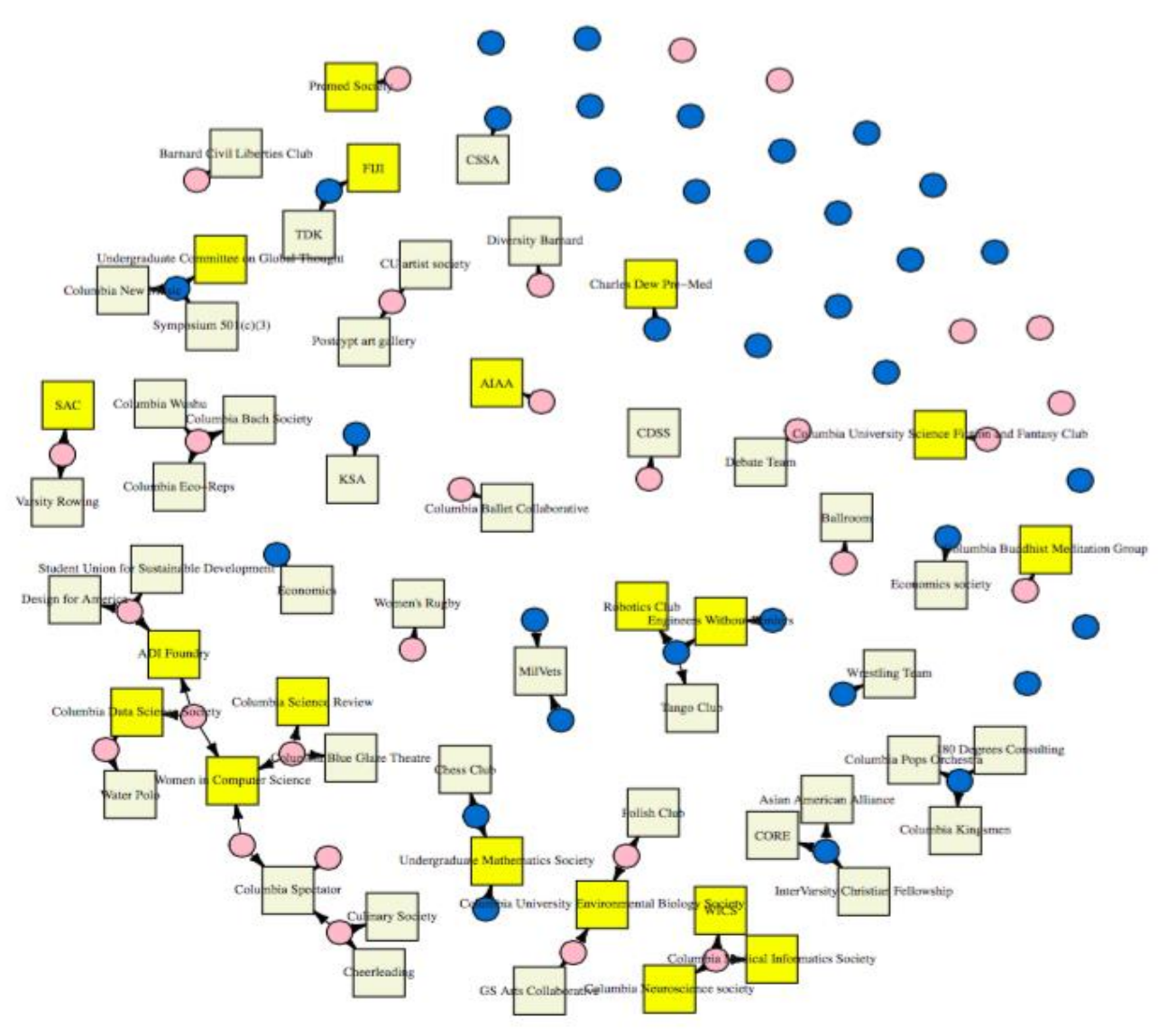

Fig. 17 Club membership network at college

(female student as pink and male student as blue;

STEM club as yellow and non-STEM club as beige) 


\begin{tabular}{|c|c|c|c|c|}
\hline \multicolumn{5}{|c|}{ Relationship between Gender and Club Membership } \\
\hline \multirow{4}{*}{$\begin{array}{l}\text { Observed } \\
\text { Number } \\
\text { of Edges }\end{array}$} & & Club Affiliation & No Club Affiliation & Total \\
\hline & Female & 24 & 5 & 29 \\
\hline & Male & 16 & 19 & 35 \\
\hline & Total & 40 & 24 & 64 \\
\hline \multirow{4}{*}{$\begin{array}{l}\text { Expected } \\
\text { Number } \\
\text { of Edges }\end{array}$} & & Club Affiliation & No Club Affiliation & Total \\
\hline & Female & 18.1 & 10.9 & 29 \\
\hline & Male & 21.9 & 13.1 & 35 \\
\hline & Total & 40 & 24 & 64 \\
\hline p-value & 0.0022 & & & \\
\hline
\end{tabular}

Table 7.1 Number of ties (edges) by college club membership and gender of STEM student

\begin{tabular}{|c|c|c|c|c|}
\hline \multicolumn{5}{|c|}{ Relationship between Gender and Type of Club Membership } \\
\hline \multirow{4}{*}{$\begin{array}{l}\text { Observed } \\
\text { Number } \\
\text { of Edges }\end{array}$} & & STEM Club & Non-STEM Club & Total \\
\hline & Female & 14 & 29 & 43 \\
\hline & Male & 5 & 20 & 25 \\
\hline & Total & 19 & 49 & 68 \\
\hline \multirow{4}{*}{$\begin{array}{l}\text { Expected } \\
\text { Number } \\
\text { of Edges }\end{array}$} & & STEM Club & Non-STEM Club & Total \\
\hline & Female & 12 & 31 & 43 \\
\hline & Male & 7 & 18 & 25 \\
\hline & Total & 19 & 49 & 68 \\
\hline p-value & 0.26 & & & \\
\hline
\end{tabular}

Table 7.2 Number of ties (edges) by type of college club and gender 


\section{- Hypothesis 5: Perceived STEM Community Integration at College Differs by Gender}

We assumed that the perceived sense of integration into the STEM college community would differ by gender, more specifically, that women would be less integrated into college STEM communities than men. To our surprise, women actually reported slightly higher, though not statistically significantly higher, integration than men.

Figure 18 represents the perceived level of STEM community integration (Core-MiddlePeripheral) according to gender for 41 STEM students. Using the Chi-squared test of no relationship between gender and STEM community integration at college, there is a statistically significant difference at the $\mathrm{p}<0.05$ level in the self-reported integration between women and men, as shown in Table 8. Surprisingly, men feel less integrated than women in their STEM community as 12 men reported feeling at the periphery of their community while only 3 women did. This finding challenges the common assumption that women feel less integrated in their STEM community at college. However, due to 23 missing survey responses, this question calls for further research, as we do not have enough information to interpret this finding.

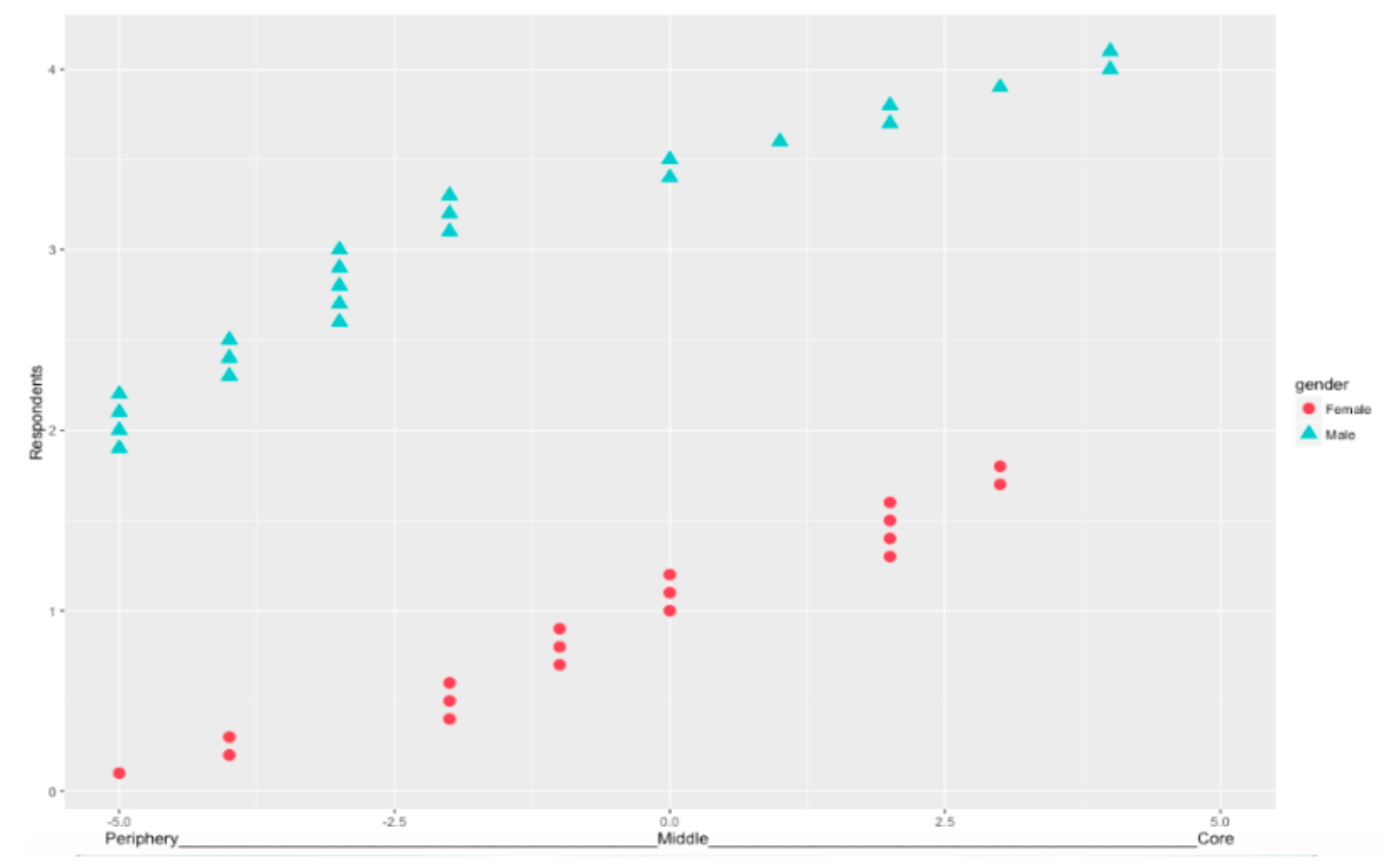

Fig. 18 Number of respondents by gender per level of integration in STEM community at college (core-middle-periphery) 


\begin{tabular}{|c|c|c|c|c|c|}
\hline \multicolumn{6}{|c|}{ Relationship between Gender and Level of Integration in STEM Community } \\
\hline \multirow{4}{*}{$\begin{array}{l}\text { Observed } \\
\text { Number of } \\
\text { Respondents }\end{array}$} & & Periphery $[-5 ;-3]$ & Middle $[-2 ; 2]$ & Core $[3 ; 5]$ & Total \\
\hline & Female & 3 & 13 & 2 & 18 \\
\hline & Male & 12 & 8 & 3 & 23 \\
\hline & Total & 15 & 21 & 5 & 41 \\
\hline \multirow{4}{*}{$\begin{array}{l}\text { Expected } \\
\text { Number of } \\
\text { Respondents }\end{array}$} & & Periphery $[-5 ;-3]$ & Middle $[-2 ; 2]$ & Core $[3 ; 5]$ & Total \\
\hline & Female & 6.6 & 9.2 & 2.2 & 18 \\
\hline & Male & 8.4 & 11.8 & 2.8 & 23 \\
\hline & Total & 15 & 21 & 5 & 41 \\
\hline p-value & 0.04 & & & & \\
\hline
\end{tabular}

Table 8 Number of respondents by gender per level of integration in STEM community

\section{○ Hypothesis 6: Perceived Confrontation with Male versus Female Professor Differs by Gender}

We assumed that the perceived student's attitude towards a professor would differ by the student's gender and professor's gender. Figure 19 compares the dynamics between 43 of the 64 respondents in relation to a female or a male professor. Due to the limited number of responses, we cannot make any substantial conclusion. However, we observe a trend: male students are more likely than women to confront and discuss with someone else (coded as blue) regardless of the gender of the professor. In front of a male professor, 7 male respondents as opposed to 4 female respondents adopt this confrontational attitude. In front of a female professor, 8 male respondents as opposed to 6 female respondents adopt this confrontational attitude. As a second trend, female students seem to be more likely to speak up and accept the professor's solution when the professor persists (coded as purple) if the professor is female (4 survey answers) as opposed to male ( 2 survey answers) while for male students, the contrary seems to occur as we notice only 1 survey answer in the presence of a female professor and a higher number of survey answers (3) when the professor is male.

Question Randomly assigned Option 1- Male Professor: You think you may have found an alternative solution to a case you have been working on. When you bring this solution to your professor, he quickly dismisses your solution and insists you follow his authoritative way to solve the problem. Given the situation, how would you respond?

Question Randomly assigned Option2 - Female Professor You think you may have found an alternative solution to a case you have been working on. When you bring this solution to your professor, she quickly dismisses your solution and insists you follow her authoritative way to solve the problem. Given the situation, how would you respond?
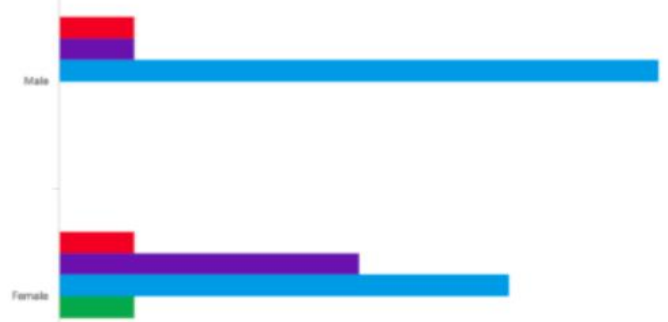


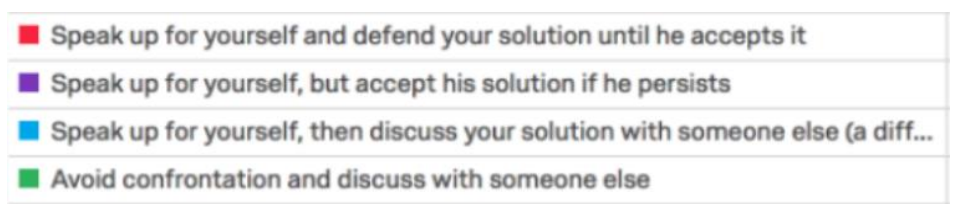

Fig. 19 Number of female and male respondents per answer to question on professor-respondent dynamics at college by gender of professor

\section{- Hypothesis 7: Peer Study Group Differs by Gender}

As we assumed a lack of integration into the STEM community for women, we anticipated women's peer study group to differ from that of men. Figure 20 shows the network of people with whom respondents talk about STEM or study STEM. We included the ego (the respondent) in the plot to assess its centrality within its peer network. While the limited number of ego surveyed calls for further research, the birth of a trend is visible. Respondents from the Computer Science Department at Columbia University clearly exhibit gender homophily in their ego network. As indicates Figure 20, both male and female respondents majoring in Computer Science show a tendency to discuss and study STEM with people of the same gender. For ego networks in other STEM majors, respondents show a higher level of intermingling (average Index of Qualitative Variation for male $=0.416$; average IQV for female $=0.57$ ). If this trend in its infancy is confirmed, it could mean that, to discuss and study STEM, women are either not accepted in male STEM groups or more comfortable in a female STEM group. Considering the negligible number of women in some STEM classes, women might have a harder time than men to form a social and academic female group to support them in persisting with their studies in STEM.

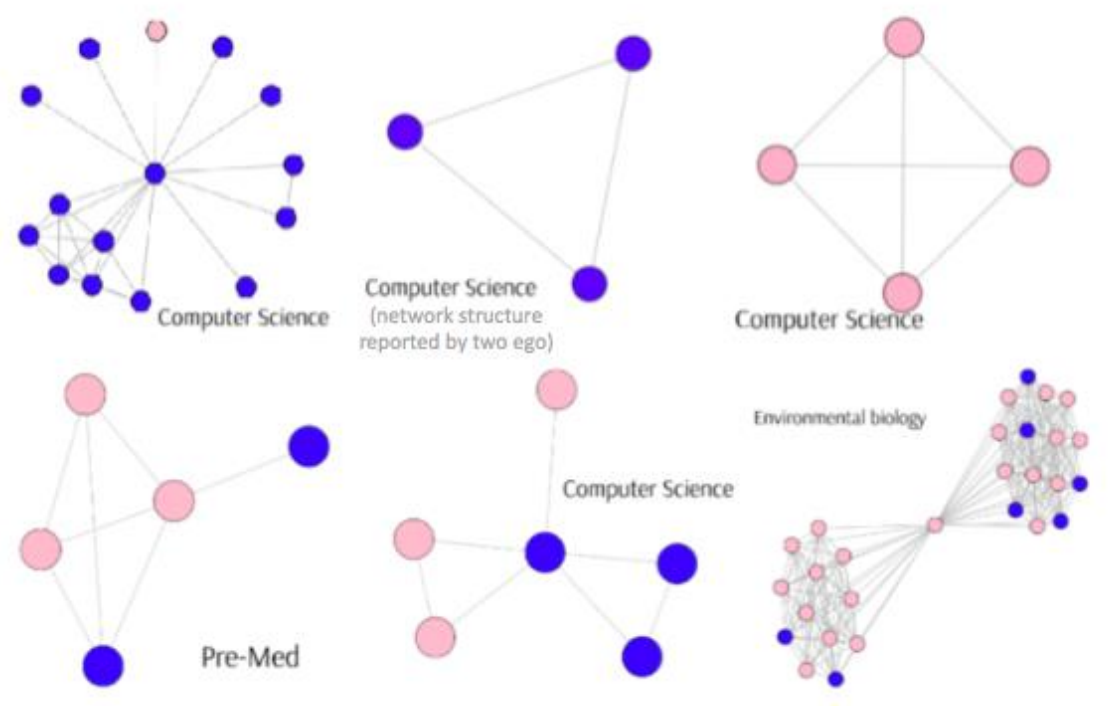

Fig. 20 Ego network at college of 7 STEM students with their respective major (female student as pink and male student as blue) 


\section{○ Hypothesis 8: Perceived Influence of Public Figures Does Not Differ by Gender}

Given the relatively lower number of mediatized female scientists, we assumed that women would derive inspiration from male scientists to engage with STEM, and as a consequence, that the perceived influence of public figures would not drastically differ by gender. Our findings confirm that women perceive most of their STEM influence from STEM male public figure (sum of weighted influences $=21$, weight for one influence ranging from -5 to 5). However, to our surprise, women reported a higher aggregate amount of weighted influence from non-STEM women figures (18) than STEM women figures (14).

Figure 21 represents whether 23 out of 64 women and men are influenced by STEM related public figures of a specific gender. A significant difference at the $\mathrm{p}<0.05$ level is observed between women and men in terms of the gender of the self-reported public figure that most influenced them to pursue STEM, as indicated by the Chi-squared test in Table 9. The finding shows a tendency towards gender homophily for both men and women. For instance, women have a higher sum of weighted influences coming from women non-STEM figures (18) than men non-STEM figures (15).

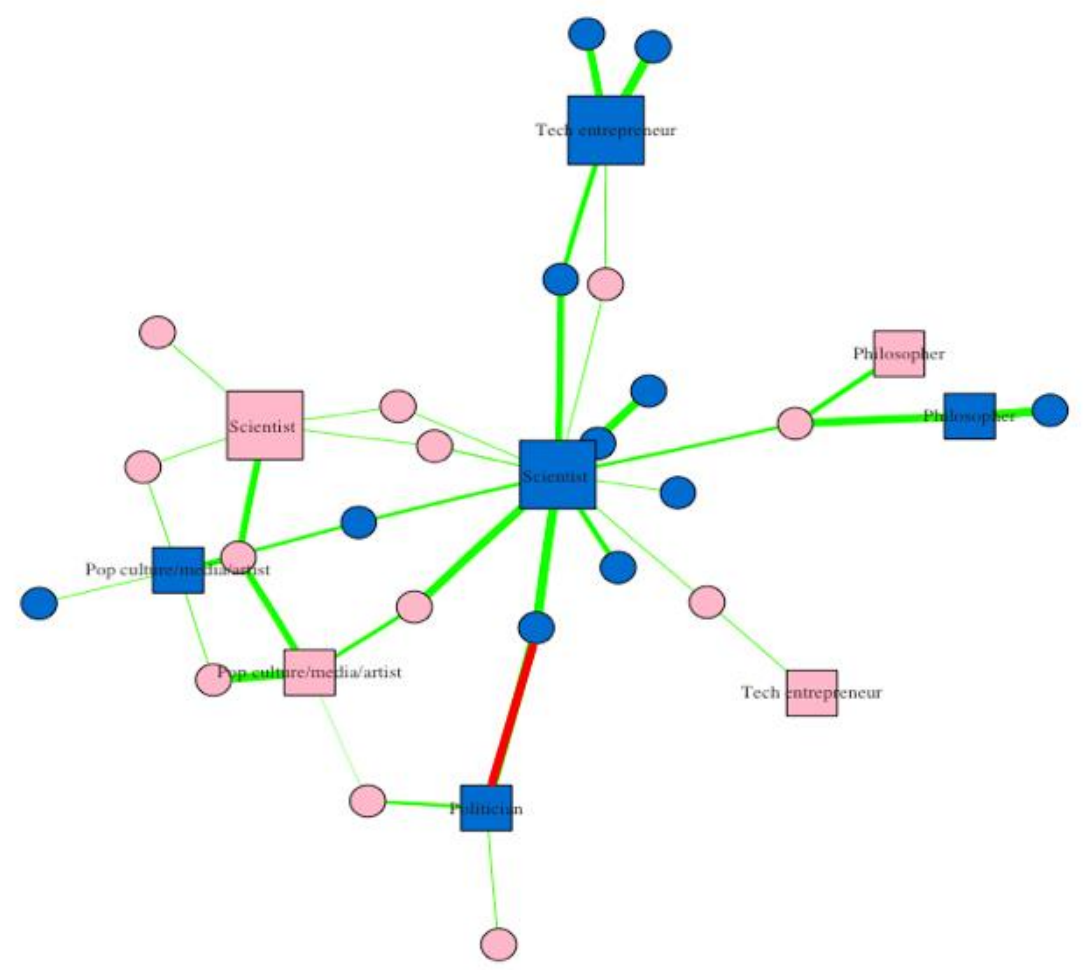

Fig. 21 Network of public figures' influence on students

(public figure as square and student as circle, female student as pink and male student as blue) 


\begin{tabular}{|c|c|c|c|c|c|c|}
\hline \multicolumn{7}{|c|}{ Relationship between Gender and Type of Influential Public Figure } \\
\hline \multirow{4}{*}{$\begin{array}{l}\text { Observed } \\
\text { Sum of } \\
\text { Influences }\end{array}$} & & STEM Women Figure & Non-STEM Women Figure & STEM Men Figure & Non-STEM Men Figure & Total \\
\hline & Female & 14 & 18 & 21 & 15 & 68 \\
\hline & Male & 0 & 0 & 41 & 11 & 52 \\
\hline & Total & 14 & 18 & 62 & 26 & 120 \\
\hline \multirow{4}{*}{$\begin{array}{l}\text { Expected } \\
\text { Sum of } \\
\text { Influences }\end{array}$} & & STEM Women Figure & Non-STEM Women Figure & STEM Men Figure & Non-STEM Men Figure & Total \\
\hline & Female & 7.9 & 10.2 & 35.1 & 14.7 & 68 \\
\hline & Male & 6.1 & 7.8 & 26.9 & 11.3 & 52 \\
\hline & Total & 14 & 18 & 62 & 26 & 120 \\
\hline p-value & $3.5 \mathrm{E}-08$ & & & & & \\
\hline
\end{tabular}

Table 9 Sum of weighted influence by type of public figure and gender of STEM student (scaled from -5 to 5 )

\section{○ Hypothesis 9: Perceived Influence of Objects Differs by Gender}

We assumed that the type of objects to which women would be sensitive would be different from the ones of men. Figure 22 shows the influence of STEM and non-STEM related objects on 20 out of 64 women and men who study STEM. STEM related objects are represented with yellow squares and non-STEM related objects with beige squares. This network indicates that women are significantly more influenced by STEM related objects than men are at the $\mathrm{p}<0.05$ level, as reflected by the Chi-squared test in Table 10. Both men and women reported STEM-related object as influential to their path to STEM, 38 and 49 aggregated weighted influences respectively (weight for one influence ranging from -5 to 5). Just as women seem to find a STEM inspiration in non-STEM women public figures, female respondents seem to find STEM inspiration in non-STEM objects (25 out of 74 weighted influences among female respondents). Surprisingly, men report a negative aggregate weighted amount of influence from non-STEM objects (-4).

According to the information given by our female respondents, women are more influenced by stories and experiences of women in STEM, while only men reported objects such as games and products as their source of inclination towards STEM. 


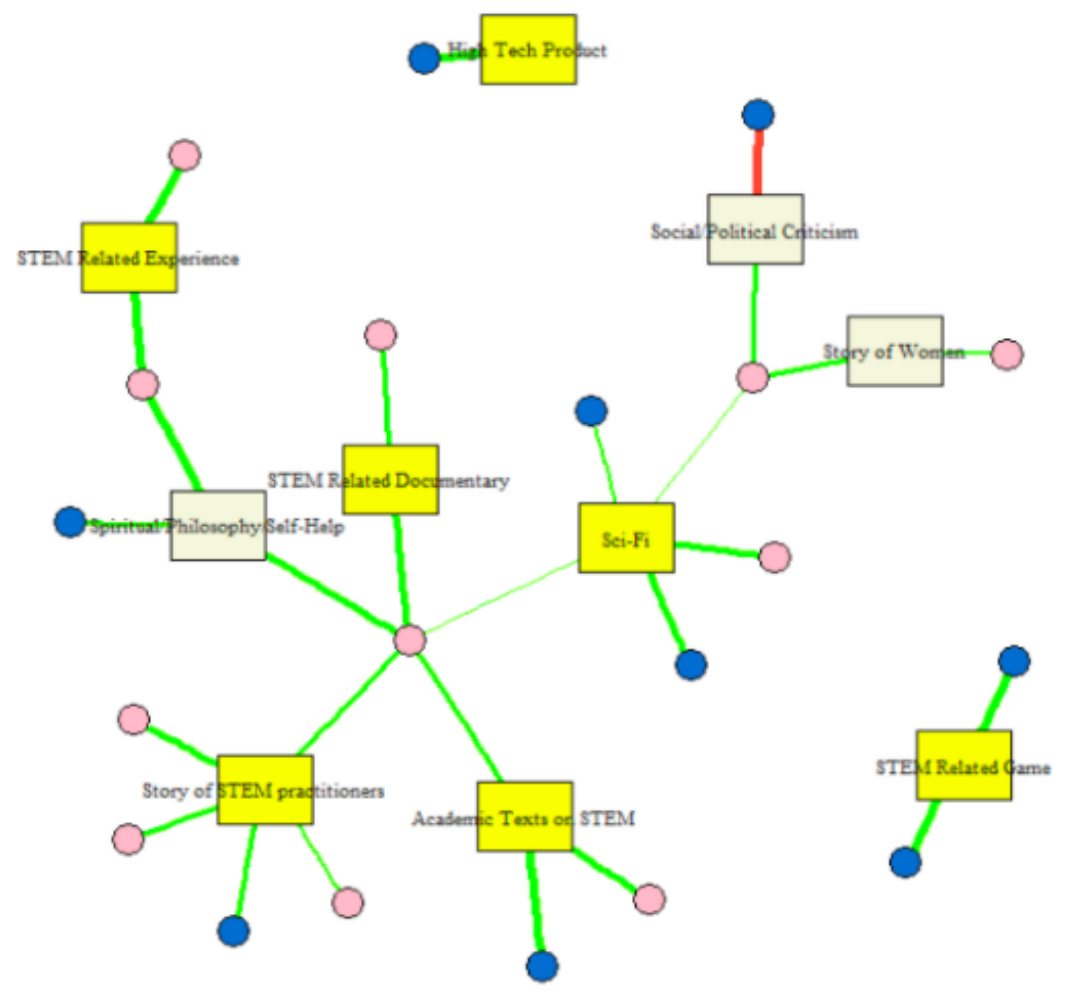

Fig. 22 Network of objects' influence on students' orientation towards STEM (object as square and student as circle, female student as pink and male student as blue, object as yellow for STEM-related and beige for non-STEM related)

\begin{tabular}{|c|c|c|c|c|}
\hline \multicolumn{5}{|c|}{ Relationship between Gender and Type of Influential Object } \\
\hline \multirow{4}{*}{$\begin{array}{l}\text { Observed } \\
\text { Sum of } \\
\text { Influences }\end{array}$} & & STEM Objects & Non-STEM Objects & Total \\
\hline & Female & 49 & 25 & 74 \\
\hline & Male & 38 & -4 & 34 \\
\hline & Total & 87 & 21 & 108 \\
\hline \multirow{4}{*}{$\begin{array}{l}\text { Expected } \\
\text { Sum of } \\
\text { Influences }\end{array}$} & & STEM Objects & Non-STEM Objects & Total \\
\hline & Female & 59.6 & 14.4 & 74 \\
\hline & Male & 27.4 & 6.6 & 34 \\
\hline & Total & 87 & 21 & 108 \\
\hline$p$-value & $2.8 \mathrm{E}-08$ & & & \\
\hline
\end{tabular}

Table 10 Sum of weighted influence by type of object and gender of STEM student (scaled from -5 to 5 ) 


\section{Limitations}

A potential confounder in our research may include our survey design given that our sampling has the issue of convenience bias as we targeted individuals who were easily accessible to us. We tried to offset part of the bias by distributing the survey through university STEM clubs and professors. Our sample may also not be adequate in terms of size for accurate generalization to the entire STEM undergraduate population at Columbia University. In addition, our survey data may include cognitive and hindsight bias from our respondents. Lastly, another confounder may appear during the survey analysis, as we did not consider 6 respondents' answers due to their incomplete responses to more than half of the survey.

\section{Conclusion}

In this article, we show that women and men who currently study STEM at college similarly perceive their individual personality traits related to the practice of STEM. More specifically, women and men report a similar approach to understanding (through Observing, Thinking, or Doing), a similar role while solving a problem in a group (consisting in Planning, Implementing, or Leading), and a similar motivation to solve a problem (resting in Challenging themself, Competing with others, or Finding solutions). Furthermore, women and men tend to derive value from science problems in the same manner. Women tend to prefer the discovery process within science slightly more, while men tend to care a little more about the findings.

Apart from these STEM-related individual similarities between women and men, our survey conveys a gap in both perceived individual interest and performance in STEM during primary school. This gap nonetheless decreases in high school and disappears at college. To reach a more comprehensive view, a follow-up research could additionally sample non-STEM students to compare perception in interest and performance within the same gender across STEM and non-STEM students. Alternatively, to reach a more precise understanding of these processes throughout college, researchers could sample students with STEM interests who have not yet declared their major.

This research highlights further disparities across gender in terms of students' perceived social network support to pursue STEM. Women reported on average a negative support from their friends in primary school, and from family members other than their parents in high school. By contrast, men had on average a completely positive support network in primary school, high school, and college. Primary school is the only time during which men and women have significantly different STEM support system. In addition, women reported female public figures from science and non-science, stories, and women experience in STEM as their principal social source of influence to pursue a STEM education. By contrast, men reported male public figures from science and non-science, games, and products as their main social influences.

Future researchers could reduce the scope of their sample to a classroom size in order to be able to construct large and densely connected peer study group ego-networks. These networks could help to make sense of the surprising observation that men feel less integrated than women in their 
STEM community at college. More specifically, these ego-networks could investigate informal gender dynamics structuring STEM students' experience outside the classroom.

While our research studies the perceived selection process of students into STEM, other research efforts could focus on the perceived selection process out of STEM and into other disciplines as well as the way these processes differ by gender.

\section{Acknowledgements}

We would like to thank Peter Bearman and Mark Hoffman for their valuable and constructive suggestions.

\section{References}

Abramo G, D’Angelo CA, Murgia G. 2013. Gender differences in research collaboration. J. Informetr. 7:811-22

Acker, Joan. 1990. Hierarchies, jobs, bodies: A theory of gendered organizations. Gender \& society, 4(2):139-158.

Acker, Joan. 2006. "Inequality Regimes: Gender, Class, and Race in Organizations." Gender \& Society 20(4): 441-464

Carlone HB, Johnson A. 2007. Understanding the science experiences of successful women of color: science identity as an analytic lens. J. Res. Sci. Teach. 44(8):1187-218

Ceci SJ, Williams WM. 2011. Understanding current causes of women's underrepresentation in science. PNAS 108:3157-62

Ceci SJ, Williams WM, Barnett SM. 2009. Women's underrepresentation in science: sociocultural and biological considerations. Psychol. Bull. 135(2):218-61

Charles M, Bradley K. 2006. A matter of degrees: female underrepresentation in computer science programs cross-nationally. In Women and Information Technology: Research on the Reasons for Underrepresentation, ed. J McGrath, B Aspray, pp. 183-203. Cambridge, MA: MIT Press 
Cheryan S, Siy JO, Vichayapai M, Drury BJ, Kim S. 2011. Do female and male role models who embody STEM stereotypes hinder women's anticipated success in STEM? Soc. Psychol. Personal. Sci. 2:656-64

Chipman SF. 2005. Research on the women and mathematics issue: a personal case history. In Gender Differences in Mathematics, ed. AM Gallagher, JC Kaufman, pp. 1-24. New York: Cambridge Univ. Press

Correll, Shelley J. 2001. "Gender and the Career Choice Process: The Role of Biased Self Assessments.” American Journal of Sociology 106 (6): 1691-1730. doi:10.1086/321299.

DiPrete TA, Buchmann C. 2013. The Rise of Women: The Growing Gender Gap in Education and What It Means for American Schools. New York: Russell Sage Found.

Eccles JS. 2011b. Understanding women's achievement choices: looking back and looking forward. Psychol. Women Q. 35:510-16

Fox MF. 1991. Gender, environmental milieu, and productivity in science. In The Outer Circle, ed. H Zuckerman, J Cole, J Bruer, pp. 188-204. New York: W.W. Norton

Frome PM, Alfeld CJ, Eccles JS, Barber BL. 2006. Why don't they want a male-dominated job? An investigation of young women who changed their occupational aspirations. Educ. Res. Eval. 12:359-72

Frome PM, Archer L, Eccles JS, Barber BL. 2008. Is the desire for a family-flexible job keeping young women out of male-dominated occupations? In Gender and Occupational Outcomes: Longitudinal Assessments of Individual, Social, and Cultural Influences, ed. HMG Watt, JS Eccles, pp. 195-214. Washington, DC: Am. Psychol. Assoc.

Hyde JS, Feenema E, Ryan M, Frost LA, Hopp C. 1990b. Gender comparisons of mathematics attitudes and affect: a meta-analysis. Psychol. Women Q. 14:299-324

Kyvik S, Teigen M. 1996. Child care, research collaboration, and gender differences in scientific productivity. Sci. Technol. Hum. Values 21:54-71

Lariviere V, Ni C, Gingras Y, Cronin B, Sugimoto CR. 2015b. Global gender disparities in science. ' Nature 504:211-13

Leahey E. 2006. Gender differences in productivity: research specialization as a missing link. Gender Soc. 20:754-80 
Legewie J, DiPrete TA. 2014a. Pathways to science and engineering bachelor's degrees for men and women. Sociol. Sci. 1:41-48

Legewie J, DiPrete TA. 2014b. The high school environment and the gender gap in science and engineering. Sociol. Educ. 87:259-80

Long JS, McGinnis R. 1981. Organizational context and scientific productivity. Am. Soc. Rev. $46: 422-42$

Miller DI, Wai J. 2015. The bachelor's to Ph.D. STEM pipeline no longer leaks more women than men: a 30-year analysis. Front. Psychol. 6:37

Murphy MC, Steele CM, Gross J. 2007. Signaling threat: how situational cues affect women in math, science, and engineering settings. Psychol. Sci. 18:879-85

National Science Foundation, National Center for Science and Engineering Statistics. 2015.

"Women, Minorities, and Persons with Disabilities in Science and Engineering: 2015." Special Report NSF 15-311. Arlington, VA. http://www.nsf.gov/statistics/wmpd/.

Nguyen H-HD, Ryan AM. 2008. Does stereotype threat affect test performance of minorities and women? A meta-analysis of experimental evidence. J. Appl. Psychol. 93:1314-34

Niederle M, Vesterlund L. 2007. Do women shy away from competition? Do men compete too much? Q. J. Econ. 122:1067-101

Reuben E, Sapienza P, Zingales L. 2014. How stereotypes impair women's careers in science. PNAS 111(12):4403-8

Ridgeway, Cecilia L., and Shelley J. Correll. 2004. "Unpacking the Gender System: A Theoretical Perspective on Gender Beliefs and Social Relations." Gender and Society 18 (4): 510-31.

Ridgeway, Cecilia L. 2011. Framed by Gender: How Gender Inequality Persists in the Modern World. New York, NY: Oxford University Press.

Sheltzer JM, Smith JC. 2014. Elite male faculty in the life sciences employ fewer women. PNAS 111(28):10107- 12

Steele J, James JB, Barnett RC. 2002. Learning in a man's world: examining the perceptions of undergraduate women in male-dominated academic areas. Psychol. Women Q. 26:46-50 
Stout JG, Dasgupta N, Hunsinger M, McManus MA. 2011. STEMing the tide: using ingroup experts to inoculate women's self-concept in science, technology, engineering, and mathematics (STEM). J. Personal. Soc. Psychol. 100:255-70

Su R, Rounds J, Armstrong PI. 2009. Men and things, women and people: a meta-analysis of sex differences in interests. Psychol. Bull. 135:859-84

Xie Y, Shauman KA. 2003. Women in Science: Career Processes and Outcomes. Cambridge, MA: Harvard Univ. Press

Xie, Yu. 2012. Is American Science in Decline? Cambridge, Mass: Harvard University Press.

Xie, Yu, Michael Fang, and Kimberlee Shauman. 2015. "STEM Education.” Annual Review of Sociology 41 (1): 331-57.

West JD, Jacquet J, King MM, Correll SJ, Bergstrom CT. 2013. The role of gender in scholarly authorship. PLOS ONE 8:e66212

"Women in STEM." 2016. The White House. Accessed October 7. https://www.whitehouse.gov/node/129247. 